\title{
Microwave-Assisted Rapid Synthesis of Reduced Graphene Oxide-Based Gum Tragacanth Hydrogel Nanocomposite for Heavy Metal Ions Adsorption
}

\author{
Bhawna Sharma ${ }^{1}$, Sourbh Thakur ${ }^{1,2, *}$, Djalal Trache ${ }^{3}\left(\mathbb{D}\right.$, Hamed Yazdani Nezhad ${ }^{4}$ and \\ Vijay Kumar Thakur $5,6, *$ (D) \\ 1 School of Chemistry, Faculty of Sciences, Shoolini University, Solan, Himachal Pradesh 173229, India; \\ sharmabhanusln@gmail.com \\ 2 Center for Computational Materials Science, Institute of Physics, Slovak Academy of Sciences, \\ 84511 Bratislava, Slovakia \\ 3 UER Chimie Appliquée, Ecole Militaire Polytechnique, Bordj El-Bahri, Algiers 16046, Algeria; \\ djalaltrache@gmail.com \\ 4 Department of Mechanical Engineering and Aeronautics, City University of London, London EC1V0HB, UK; \\ hamed.yazdani@city.ac.uk \\ 5 Biorefining and Advanced Materials Research Center, Scotland's Rural College (SRUC), Kings Buildings, \\ West Mains Road, Edinburgh EH9 3JG, UK \\ 6 Department of Mechanical Engineering, School of Engineering, Shiv Nadar University, \\ Uttar Pradesh 201314, India \\ * Correspondence: thakursourbh@gmail.com or sourbh.thakur@savba.sk (S.T.); \\ vijay.thakur@sruc.ac.uk (V.K.T.)
}

Received: 28 June 2020; Accepted: 12 August 2020; Published: 18 August 2020

\begin{abstract}
Reduced graphene oxide (RGO) was synthesized in this research via Tour's method for the use of filler in the hydrogel matrix. The copolymerization of $\mathrm{N}, \mathrm{N}$-dimethylacrylamide (DMA) onto the gum tragacanth (GT) was carried out to develop gum tragacanth-cl- $N, N$-dimethylacrylamide (GT-cl-poly(DMA)) hydrogel using $N, N^{\prime}$-methylenebisacrylamide (NMBA) and potassium persulfate (KPS) as cross-linker and initiator correspondingly. The various GT-cl-poly(DMA) hydrogel synthesis parameters were optimized to achieve maximum swelling of GT-cl-poly(DMA) hydrogel. The optimized GT-cl-poly(DMA) hydrogel was then filled with RGO to form reduced graphene oxide incorporated gum tragacanth-cl- $N, N$-dimethylacrylamide (GT-cl-poly(DMA)/RGO) hydrogel composite. The synthesized samples were used for competent adsorption of $\mathrm{Hg}^{2+}$ and $\mathrm{Cr}^{6+}$ ions. Fourier transform infrared, X-ray powder diffraction, field emission scanning electron microscopy, energy-dispersive $\mathrm{X}$-ray spectroscopy were used to characterize the gum tragacanth-cl- $N, N$-dimethylacrylamide hydrogel and reduced graphene oxide incorporated gum tragacanth-cl- $N, N$-dimethylacrylamide hydrogel composite. The experiments of adsorption-desorption cycles for $\mathrm{Hg}^{2+}$ and $\mathrm{Cr}^{6+}$ ions were carried out to perform the reusability of gum tragacanth-cl- $N, N$-dimethylacrylamide hydrogel and reduced graphene oxide incorporated gum tragacanth-cl- $N, N$-dimethylacrylamide hydrogel composite. From these two samples, reduced graphene oxide incorporated gum tragacanth-cl- $N, N$-dimethylacrylamide exhibited high adsorption ability. The $\mathrm{Hg}^{2+}$ and $\mathrm{Cr}^{6+}$ ions adsorption by gum tragacanth-cl- $\mathrm{N}, \mathrm{N}$-dimethylacrylamide and reduced graphene oxide incorporated gum tragacanth-cl- $N, N$-dimethylacrylamide were best suited for pseudo-second-order kinetics and Langmuir isotherm. The reported maximum $\mathrm{Hg}^{2+}$ and $\mathrm{Cr}^{6+}$ ions adsorption capacities were $666.6 \mathrm{mg} \mathrm{g}^{-1}$ and $473.9 \mathrm{mg} \mathrm{g}^{-1}$ respectively.
\end{abstract}

Keywords: reduced graphene oxide; gum tragacanth; hydrogel; hydrogel composite; mercury ion; chromium ion; reusability 


\section{Introduction}

Continuous industrialization leads to the excessive release of toxic pollutants into various sources of water. The heavy metal poisoning of water has now become a pandemic concern due to its dangerous impacts to human health because these pollutants are non-degradable, poisonous, cancer-causing agent and are hard to separate from water [1]. For metal uptake from water, several approaches have been established, among them, treatment via adsorption is the most appealing one. Adsorption technology is widely used for removing pollutants due to its simple operation, cost and easy implementation [2]. Specifically, hydrogels based on biopolymer have now become very useful in adsorptive wastewater treatment [3]. Gum tragacanth based hydrogel is highly adsorptive because of the presence of hydroxyl $(-\mathrm{OH})$ and carboxyl $(-\mathrm{COOH})$ groups $[4,5]$. It is a renewable, cost-effective and environmentally friendly polysaccharide that can be easily polymerized to form cross-linked structures [6-8].

Gum tragacanth is commonly found in the sap of different legumes in the Middle East. The biological source of gum tragacanth is a plant named Astragalus gummifer. It is a complex mixture of polysaccharides including bassorin and tragacanthin units. When mixed with water, gum tragacanth produces a colloidal hydrosol. The bassorin unit can (composed of $60-70 \%$ of the compound) swells to form a gel [9]. Mallakpour et al. reported the glutaraldehyde cross-linked gum tragacanth/ $\mathrm{CaCO}_{3}$ hydrogel composite as an adsorbent for the abstraction of $\mathrm{Pb}^{2+}$ ion [10]. Moghaddam et al. synthesized methoxyl gum tragacanth-glutamic acid/polyacrylamide hydrogel via electron beam radiations as an adsorbent for trapping uranium ions from toxic uranium solution [11].

The adsorption and stability of hydrogel can be improved by using reduced graphene oxide as filler in the hydrogel matrix. Reduced graphene oxide (RGO) can result in high C/O with better mechanical strength [12]. The reduced graphene oxide is partially decorated with an oxygen-rich functional group that acts as active sites for interaction. The high RGO surface, large porosity and defect sites are the features that help pollutants adsorption [13]. Sahraei et al. reported adsorption of $\mathrm{Cr}^{6+} \mathrm{metal}^{\mathrm{t}}$ using chitosan/reduced-graphene oxide/montmorillonite composite hydrogel. The composite hydrogel showed maximum $\mathrm{Cr}^{6+}$ absorption of $87.03 \mathrm{mg} \mathrm{g}^{-1}$ [14]. Zhuang et al. synthesized molybdenum disulfide/RGO hydrogel as an adsorbent for mercury ions removal [15].

The synthesized gum tragacanth-cl-N,N-dimethylacrylamide (GT-cl-poly(DMA)) and reduced graphene oxide incorporated gum tragacanth-cl- $N, N$-dimethylacrylamide (GT-cl-poly(DMA)/RGO) hydrogel composite were efficient in adsorption of $\mathrm{Hg}^{2+}$ and $\mathrm{Cr}^{6+}$ as compared to previously reported adsorbents in the literature (Table 1 ). This was due to the perfect combination of reduced graphene oxide (RGO), gum tragacanth (GT), and N,N-dimethylacrylamide (DMA) led to the presence of many $-\mathrm{OH},-\mathrm{NH}_{2}$ and $-\mathrm{COOH}$ hydrophilic groups. The gum tragacanth-cl- $N, N$-dimethylacrylamide hydrogel and reduced graphene oxide incorporated gum tragacanth-cl- $N, N$-dimethylacrylamide hydrogel composite exhibited the highest removal capacity of $625 \mathrm{mg} \mathrm{g}^{-1}$ and $666.6 \mathrm{mg} \mathrm{g}^{-1}$ respectively for $\mathrm{Hg}^{2+}$. Similarly, for $\mathrm{Cr}^{6+}$, removal capacities were $401.6 \mathrm{mg} \mathrm{g}^{-1}$ and $473.9 \mathrm{mg} \mathrm{g}^{-1}$ respectively.

The previously reported works (Table 1) have not comprehensively considered the factors responsible for the high adsorption capability of the adsorbent. In this work, we achieved a better adsorption capacity of $666.6 \mathrm{mg} \mathrm{g}^{-1}$ and $473.9 \mathrm{mg} \mathrm{g}^{-1}$ for mercury and chromium ions within less time using a low adsorbent dose. Specifically, prepared reduced graphene oxide incorporated gum tragacanth cross-linked poly $N, N$-dimethylacrylamide hydrogel composite shows a very high adsorption percentage of $99 \%$ for mercury metal ion under optimal conditions (adsorbent dose $=0.035 \mathrm{~g}$ and time $=270 \mathrm{~min}, \mathrm{~T}=25^{\circ} \mathrm{C}$, the concentration of mercury solution $=20 \mathrm{ppm}$ ) which means it is highly efficient for mercury adsorption. Also, compared to recently reported studies, we are able to synthesize our adsorbents in very short period (90 s) with high swelling percentage (Table 2) using microwave radiations. This is one of the key points where our synthesis part shows novelty. Hence, we developed the simple and fast synthetic route for the preparation of efficient, sustainable and eco-friendly graphene oxide incorporated gum tragacanth-cl- $N, N$-dimethylacrylamide hydrogel with high adsorption rate for heavy metal ions. 
Table 1. Comparison of different adsorbents with gum tragacanth-cl- $N, N$-dimethylacrylamide (GT-cl-poly(DMA)) hydrogel and reduced graphene oxide incorporated gum tragacanth-cl- $N, N$-dimethylacrylamide (GT-cl-poly(DMA)/RGO) hydrogel composite for adsorption of $\mathrm{Hg}^{2+}$ and $\mathrm{Cr}^{6+}$ metal ions.

\begin{tabular}{|c|c|c|c|c|}
\hline Serial Number & Adsorbent & $\begin{array}{l}\mathrm{Hg}^{2+} \text { Adsorption } \\
\text { Capacity }\left(\mathrm{mg} \mathrm{g}^{-1}\right)\end{array}$ & $\begin{array}{l}\mathrm{Cr}^{6+} \text { Adsorption } \\
\text { Capacity }\left(\mathrm{mg} \mathrm{g}^{-1}\right)\end{array}$ & References \\
\hline 1. & $\begin{array}{l}\text { Poly(allylamine-co-methacrylamide- } \\
\text { co-dimethylthiourea) }\end{array}$ & 198.23 & - & [16] \\
\hline 2. & $\begin{array}{l}\text { Sulfhydryl-functional paramagnetic } \\
\text { solid-phase adsorbent }\end{array}$ & 51.32 & - & [17] \\
\hline 3. & $\begin{array}{l}\text { Diethylenetriaminepentaacetic } \\
\text { acid-modified cellulose adsorbent }\end{array}$ & 476.2 & - & [18] \\
\hline 4. & $\begin{array}{l}\text { Cross-linked magnetic } \\
\text { chitosan-phenylthiourea resin }\end{array}$ & 135.5 & - & [19] \\
\hline 5. & $\begin{array}{l}\text { Carboxyl methylcellulose and } \\
\text { chitosan-derived nanostructured }\end{array}$ & - & 347.0 & [20] \\
\hline 6. & $\begin{array}{l}\text { Carboxymethyl cellulose-stabilized } \\
\text { sulfidated nano zerovalent iron }\end{array}$ & - & 355.9 & [21] \\
\hline 7. & Fungal strain (Rhizopus sp.) & - & 9.95 & [22] \\
\hline 8. & $\begin{array}{l}\text { Surfactant-modified Auricularia } \\
\text { auricula spent substrate }\end{array}$ & - & 21.74 & [23] \\
\hline 9. & $\begin{array}{l}\text { GT-cl-poly(DMA) hydrogel and } \\
\text { GT-cl-poly(DMA)/RGO } \\
\text { hydrogel composite }\end{array}$ & $\begin{array}{l}636.94 \\
\text { and } \\
666.66\end{array}$ & - & Present work \\
\hline 10. & $\begin{array}{l}\text { GT-cl-poly(DMA) hydrogel and } \\
\text { GT-cl-poly(DMA)/RGO } \\
\text { hydrogel composite }\end{array}$ & - & $\begin{array}{l}416.66 \\
\text { and } \\
476.19\end{array}$ & Present work \\
\hline
\end{tabular}

Table 2. Comparative analysis for swelling percentage of hydrogels.

\begin{tabular}{|c|c|c|c|c|c|}
\hline Serial Number & Sample & $\begin{array}{l}\text { Synthetic } \\
\text { Route }\end{array}$ & $\begin{array}{c}\text { Time for } \\
\text { Synthesis (s) }\end{array}$ & $\begin{array}{c}\text { Swelling } \\
\text { Percentage (\%) }\end{array}$ & References \\
\hline 1. & $\begin{array}{c}\text { Carboxymethyl } \\
\text { cellulose-cl-poly(lactic } \\
\text { acid- } \\
\text { co-itaconic acid) } \\
\text { hydrogel }\end{array}$ & $\begin{array}{l}\text { Microwave } \\
\text { assisted } \\
\text { method }\end{array}$ & $90 \mathrm{~s}$ & $332 \%$ & [24] \\
\hline 2. & $\begin{array}{c}\text { Tragacanth } \\
\text { gum-g-poly(itaconic } \\
\text { acid) hydrogel }\end{array}$ & $\begin{array}{l}\text { Microwave-assisted } \\
\text { method }\end{array}$ & $220 \mathrm{~s}$ & $800 \%$ & [25] \\
\hline 3. & $\begin{array}{l}\text { Chitosan-polyethylene } \\
\text { glycol hydrogel } \\
\text { membrane }\end{array}$ & $\begin{array}{l}\text { Microwave } \\
\text { assisted } \\
\text { method }\end{array}$ & $120 \mathrm{~s}$ & $96.4 \%$ & [26] \\
\hline 4. & $\begin{array}{l}\text { IPN [(GcA-coll)-cl-poly } \\
\text { (AAm-ip-AA)] }\end{array}$ & $\begin{array}{l}\text { Microwave } \\
\text { assisted } \\
\text { method }\end{array}$ & $150 \mathrm{~s}$ & $382.1 \%$ & [27] \\
\hline 5. & $\begin{array}{l}\text { GT-cl-poly(DMA) } \\
\text { hydrogel }\end{array}$ & $\begin{array}{l}\text { Microwave } \\
\text { assisted } \\
\text { method }\end{array}$ & $90 \mathrm{~s}$ & $957.2 \%$ & Present work \\
\hline 6. & $\begin{array}{l}\text { GT-cl-poly(DMA)/RGO } \\
\text { hydrogel composite }\end{array}$ & $\begin{array}{l}\text { Microwave } \\
\text { assisted } \\
\text { method }\end{array}$ & $90 \mathrm{~s}$ & $971.9 \%$ & Present work \\
\hline
\end{tabular}

In this work, we developed first-time gum tragacanth-cl- $N, N$-dimethylacrylamide hydrogel and reduced graphene oxide incorporated gum tragacanth-cl- $N, N$-dimethylacrylamide hydrogel composite for adsorption of $\mathrm{Hg}^{2+}$ and $\mathrm{Cr}^{6+}$. The $\mathrm{RGO}$ was synthesized from graphite and incorporated in GT-cl-poly(DMA) hydrogel matrix to increase the adsorption efficiency. The sorption study was explained by kinetic and isotherm models. The effect of $\mathrm{pH}$, adsorbent dose and RGO loading on adsorption were performed. The gum tragacanth-cl- $N, N$-dimethylacrylamide hydrogel was systematically designed based on swelling. The adsorbed samples were desorbed successfully by using $0.1 \mathrm{M} \mathrm{HNO}_{3}$ and used further for adsorption experiments. 


\section{Materials and Methods}

\subsection{Materials}

Gum tragacanth $(\mathrm{GT})$, (molecular weight $=8.4 \times 10^{5} \mathrm{~g} \mathrm{~mol}^{-1}$ ), potassium persulfate (KPS), $N, N^{\prime}$-methylenebisacrylamide (NMBA), N,N-dimethylacrylamide (DMA) were purchased from Sigma-Aldrich (Sigma Aldrich Chemicals Pvt. Ltd., Delhi, India). Graphite powder, $\mathrm{H}_{3} \mathrm{PO}_{4}, \mathrm{KMnO}_{4}$, $\mathrm{H}_{2} \mathrm{O}_{2}$ and concentrated $\mathrm{H}_{2} \mathrm{SO}_{4}(98 \mathrm{wt} \%$ ) were obtained from LOBA-Chemie (Loba Chemie Pvt. Ltd., Tarapur, Maharashtra, India). $\mathrm{Hg}^{2+}$ and $\mathrm{Cr}^{6+}$ ions solutions were obtained by dissolving mercury chloride (Sigma Aldrich Chemicals Pvt. Ltd., Delhi, India) and potassium chromate (Sigma Aldrich Chemicals Pvt. Ltd., Delhi, India) reagents in distilled water.

\subsection{Synthesis of Reduced Graphene Oxide (RGO)}

For the synthesis, a mixture of $50 \mathrm{~mL}$ concentrated $\mathrm{H}_{2} \mathrm{SO}_{4}$ and $5.5 \mathrm{~mL}$ of $\mathrm{H}_{3} \mathrm{PO}_{4}$ was taken in a beaker. Then, $1.0 \mathrm{~g}$ of graphite powder and $\mathrm{KMnO}_{4}(4.0 \mathrm{~g})$ were added to the mixture after maintaining $10{ }^{\circ} \mathrm{C}$ under magnetic stirring in ice bath. The mixture was heated to $35^{\circ} \mathrm{C}$ governed by a water bath. After $2 \mathrm{~h}$ of stirring, the reaction mixture was sonicated 10 times with the help of ultrasonicator. To stop the reaction, deionized water $(200 \mathrm{~mL})$ and $1 \mathrm{M} \mathrm{NaOH}$ solution were added dropwise to maintain the $\mathrm{pH}=6$ of solution mixture. The reaction process was then followed with the addition of $\mathrm{H}_{2} \mathrm{O}_{2}(15 \mathrm{~mL})$ which led to a change in suspension color to yellow. The mixture was kept overnight. Thereafter, the solution of ascorbic acid $\left(0.227 \mathrm{~mol} \mathrm{~L}{ }^{-1}\right)$ was added dropwise under magnetic stirring at $95^{\circ} \mathrm{C}$. In this step, the color of the solution changes slowly from greenish-yellow to black. Finally, the mixture was allowed to settle down for $1 \mathrm{~h}$. Black precipitates were formed which were then centrifuged and washed several times using ethanol.

\subsection{Synthesis of Gum Tragacanth-cl-N,N-dimethylacrylamide (GT-cl-poly(DMA)) Hydrogel}

Microwave-assisted copolymerization method was used in the synthesis of gum tragacanth-cl- $N, N$-dimethylacrylamide hydrogel [5]. In a typical reaction, $0.5 \mathrm{~g}$ of gum tragacanth (GT) (in $11 \mathrm{~mL}$ of deionized water) was taken in $50 \mathrm{~mL}$ beaker, stirred until GT was uniformly mixed with distilled water. After this, KPS $\left(10 \times 10^{-1}\right.$ mol L $\left.{ }^{-1}\right)$ and NMBA $\left(5.8 \times 10^{-1} \mathrm{~mol} \mathrm{~L}^{-1}\right)$ were added into the GT solution. Magnetic stirring was continued to get a homogenous mixture and then $4.4 \times 10^{-1} \mathrm{~mol} \mathrm{~L}^{-1}$ of DMA was added in this mixture. The solution mixture was placed under microwave radiations for $90 \mathrm{~s}$ to generate active radicals needed for the initiation of the polymerization reaction. The prepared gel was washed using acetone and dried inside the preheated $\left(50{ }^{\circ} \mathrm{C}\right)$ hot air oven for $24 \mathrm{~h}$.

\subsection{Synthesis of Reduced Graphene Oxide Incorporated Gum Tragacanth-cl-N,N-dimethylacrylamide (GT-cl-poly(DMA)/RGO) Hydrogel Composite}

For the preparation of reduced graphene oxide incorporated gum tragacanth-cl- $N, N$-dimethylacrylamide hydrogel composite, $0.5 \mathrm{~g}$ of GT was added in a solution of RGO (0.005-0.025 g in $11 \mathrm{~mL}$ of deionized water). Physical agitation was applied until the mixture becomes homogenously uniform. Thereafter, the mixture was treated similarly following the procedure in Section 2.3. The incorporation of RGO was confirmed physically by monitoring the color change from light orange to black, as presented in Scheme 1. The optimized quantities that are used in the preparation of hydrogels are given in Table 3. 

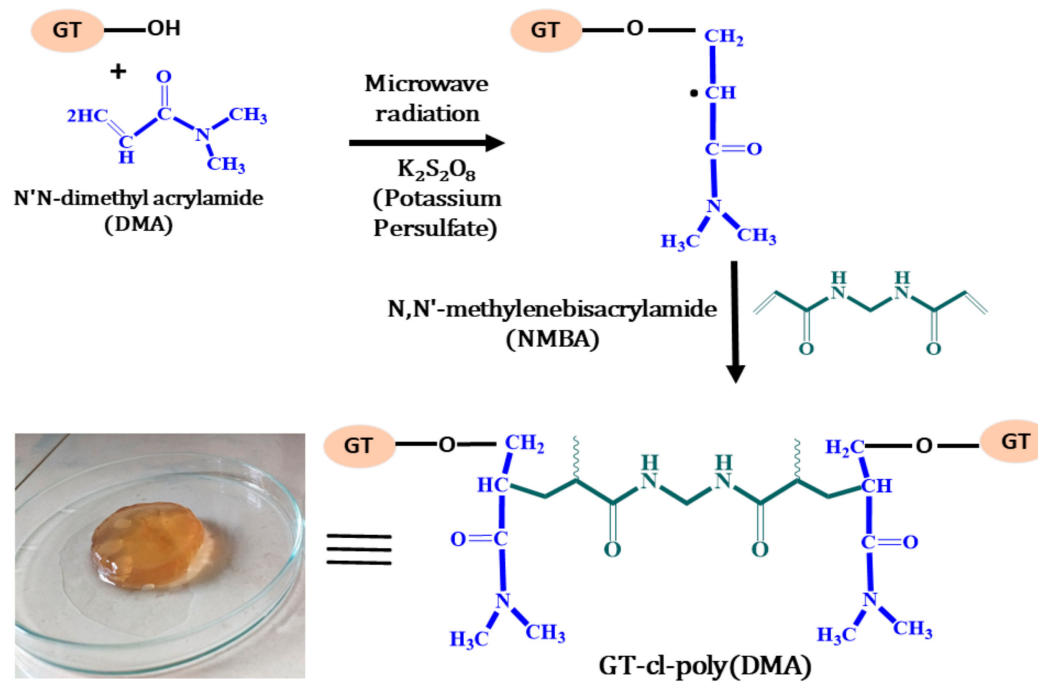

-cl-poly(DMA)

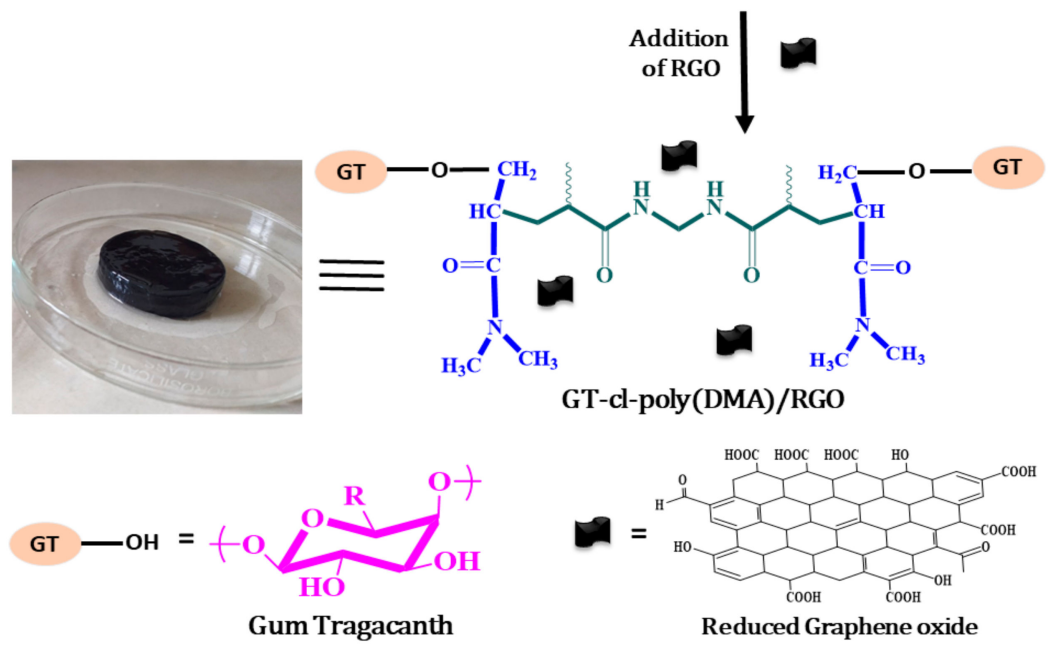

Scheme 1. General scheme for the synthesis of gum tragacanth-cl- $N, N$-dimethylacrylamide hydrogel and reduced graphene oxide incorporated gum tragacanth-cl- $N, N$-dimethylacrylamide hydrogel composite.

Table 3. Optimized quantities used for the preparation of hydrogels.

\begin{tabular}{ccccccccc}
\hline $\begin{array}{c}\text { Serial } \\
\text { Number }\end{array}$ & Sample Name & $\begin{array}{c}\text { GT } \\
(\mathbf{g})\end{array}$ & $\begin{array}{c}\text { KPS } \\
(\mathbf{g})\end{array}$ & $\begin{array}{c}\text { DMA } \\
(\mathbf{m L})\end{array}$ & $\begin{array}{c}\text { NMBA } \\
(\mathbf{g})\end{array}$ & $\begin{array}{c}\text { Solvent } \\
(\mathbf{m L})\end{array}$ & $\begin{array}{c}\text { RGO } \\
(\mathbf{g})\end{array}$ & $\begin{array}{c}\text { Swelling } \\
\mathbf{\%}\end{array}$ \\
\hline 1. & $\begin{array}{c}\text { GT-cl-poly(DMA) hydrogel } \\
\text { GT-cl-poly(DMA)/RGO } \\
\text { hydrogel composite }\end{array}$ & 0.500 & 0.030 & 0.5 & 0.030 & 11 & - & $957.2 \%$ \\
2. & 0.500 & 0.030 & 0.5 & 0.030 & 11 & 0.020 & $971.9 \%$ \\
\hline
\end{tabular}

\subsection{Characterization}

Fourier transform infrared spectra of GT, RGO, gum tragacanth-cl- $N, N$-dimethylacrylamide hydrogel and reduced graphene oxide incorporated gum tragacanth-cl- $N, N$-dimethylacrylamide hydrogel composite were measured through L1600312 spectrum TWOLITA/ZnSe FTIR spectrophotometer (Agilent Technologies, Santa Clara, CA, USA). Field emission scanning electron microscopy images were collected at different resolutions from a Nova Nano SEM-450 FESEM (JFEI, USA (S.E.A.), Hillsboro, ORE, USA). X-ray powder diffraction was collected from a SmartLab $9 \mathrm{~kW}$ rotating anode $\mathrm{x}$-ray diffractometer (Rigaku Corporation, Tokyo, Japan). 


\subsection{Swelling Study}

Various parameters such as initiator concentration (KPS) solvent volume, time, cross-linker concentration (NMBA), microwave power, monomer concentration (DMA) and amount of RGO were optimized to obtain the maximum swelling percentage. The swelling percentages of gum tragacanth-cl- $N, N$-dimethylacrylamide and reduced graphene oxide incorporated gum tragacanth-cl- $N, N$-dimethylacrylamide hydrogels in deionized water were examined for a fixed period of $16 \mathrm{~h}$. The pre-weighed dry piece of the sample was added in $50 \mathrm{~mL}$ of distilled water for $16 \mathrm{~h}$. Then, swelled hydrogel was weighed. The swelling percentage was calculated using Equation (1) [28]:

$$
\text { Swelling } \%=\frac{\mathrm{W}_{\mathrm{s}}-\mathrm{W}_{\mathrm{d}}}{\mathrm{W}_{\mathrm{d}}} \times 100
$$

where, $\mathrm{W}_{\mathrm{s}}=$ weight of swelled gum tragacanth-cl- $N, N$-dimethylacrylamide hydrogel, $\mathrm{W}_{\mathrm{d}}=$ weight of dry gum tragacanth-cl- $N, N$-dimethylacrylamide hydrogel.

\subsection{Adsorption of $\mathrm{Hg}^{2+}$ and $\mathrm{Cr}^{6+}$}

The batch adsorption analyses were performed in $150 \mathrm{~mL}$ beaker using adsorption shaker ( $200 \mathrm{rpm})$ at $\mathrm{pH}$ of 5.5 and 3.5 for $\mathrm{Hg}^{2+}$ and $\mathrm{Cr}^{6+}$ removal respectively. For more illustration, $0.010-0.070 \mathrm{~g}$ of adsorbents were used in $\mathrm{Hg}^{2+}$ and $\mathrm{Cr}^{6+}$ ions solution $\left(50 \mathrm{~mL}, 20 \mathrm{ppm}\right.$ ) at $25^{\circ} \mathrm{C}$ for fixed period. After adsorption, the mixture was filtered to determine the concentration of $\mathrm{Hg}^{2+}$ and $\mathrm{Cr}^{6+}$ ions using 1,3-diphenylcarbazide method [14]. The concentration of adsorbed $\mathrm{Hg}^{2+}$ and $\mathrm{Cr}^{6+}$ was calculated by evaluating the absorbance of heavy metal ion solution using UV-Vis spectrophotometer at $532 \mathrm{~nm}$ and $370 \mathrm{~nm}$ respectively. The amount of adsorbed $\mathrm{Hg}^{2+}$ and $\mathrm{Cr}^{6+}$ was calculated by Equation (2) [28]:

$$
\mathrm{q}_{\mathrm{e}}=\frac{\left(\mathrm{C}_{\mathrm{o}}-\mathrm{C}_{\mathrm{e}}\right) \mathrm{V}}{\mathrm{M}}
$$

where $\mathrm{q}_{\mathrm{e}}=$ equilibrium gum tragacanth-cl- $N, N$-dimethylacrylamide and reduced graphene oxide incorporated gum tragacanth-cl- $N, N$-dimethylacrylamide adsorption capacity, $\mathrm{C}_{\mathrm{o}}=$ initial $\mathrm{Hg}^{2+}$ and $\mathrm{Cr}^{6+}$ concentration $\left(\mathrm{mg} \mathrm{L}^{-1}\right), \mathrm{C}_{\mathrm{e}}=$ equilibrium $\mathrm{Hg}^{2+}$ and $\mathrm{Cr}^{6+}$ concentration $\left(\mathrm{mg} \mathrm{L}^{-1}\right), \mathrm{V}=$ volume (L) of $\mathrm{Hg}^{2+}$ and $\mathrm{Cr}^{6+}$ ion solution, $\mathrm{M}=$ weight $(\mathrm{g})$ of gum tragacanth-cl- $N, N$-dimethylacrylamide and reduced graphene oxide incorporated gum tragacanth-cl- $N, N$-dimethylacrylamide hydrogels. Adsorption-desorption analyses were conducted by using $0.1 \mathrm{M} \mathrm{HNO}_{3}$. We have optimized the $\mathrm{HNO}_{3}$ concentration $(0.02 \mathrm{M}, 0.04 \mathrm{M}, 0.06 \mathrm{M}, 0.08 \mathrm{M}, 0.1 \mathrm{M}, 0.12 \mathrm{M})$ for desorption experiments. The maximum adsorption-desorption rate was found at optimized $0.1 \mathrm{M} \mathrm{HNO}_{3}$. The $\mathrm{Hg}^{2+}$ and $\mathrm{Cr}^{6+}$ loaded GT-cl-poly(DMA) hydrogel and GT-cl-poly(DMA)/RGO hydrogel composite were desorbed by using $100 \mathrm{~mL}$ of $0.1 \mathrm{M} \mathrm{HNO}_{3}$ followed by neutralization with $0.1 \mathrm{M} \mathrm{NaOH}$. Finally, the desorbed adsorbent was washed by distilled water and dried at room temperature for further adsorption of $\mathrm{Hg}^{2+}$ and $\mathrm{Cr}^{6+}$.

\section{Results}

\subsection{Mechanism for Synthesis of Gum Tragacanth-cl-N,N-dimethylacrylamide Hydrogel}

In this work, gum tragacanth-cl- $N, N$-dimethylacrylamide hydrogel and reduced graphene oxide incorporated gum tragacanth-cl- $N, N$-dimethylacrylamide hydrogel composite were prepared by radical copolymerization of DMA and GT in the presence radical initiator (KPS) and the cross-linking action of NMBA. Under microwave radiations, KPS was decomposed and radical ions were generated [25]. These primary free radicals led to the generation of DMA monomer radical (through addition reaction with KPS) and GT alkoxy radical (through abstraction of hydrogen by KPS). The grafting of DMA radical and GT alkoxy radical was carried through radical copolymerization reaction (Scheme 1). The crosslinker NMBA led to the cross-linkages between different chains to facilitate the 
construction of three-dimensional gum tragacanth-cl- $N, N$-dimethylacrylamide hydrogel polymeric network. Finally, the dispersion of RGO led to the generation of reduced graphene oxide incorporated gum tragacanth-cl- $N, N$-dimethylacrylamide hydrogel composite.

3.2. Optimization of Swelling for Reduced Graphene Oxide Incorporated Gum Tragacanth-cl-N, $\mathrm{N}$-dimethylacrylamide Hydrogel Composite

\subsubsection{Initiator (KPS) Concentration}

The swelling percentage of GT-cl-poly(DMA) hydrogel was affected by the concentration of KPS and results are shown in Figure 1a. The maximum swelling of $565.5 \%$ was observed at $10 \times 10^{-1} \mathrm{~mol} \mathrm{~L}^{-1}$ of KPS. Below this concentration $\left(<10 \times 10^{-1} \mathrm{~mol} \mathrm{~L}^{-1}\right)$, the swelling percentage was lower due to inadequate initiator, which was unable to produce appropriate active sites on GT-cl-poly(DMA).
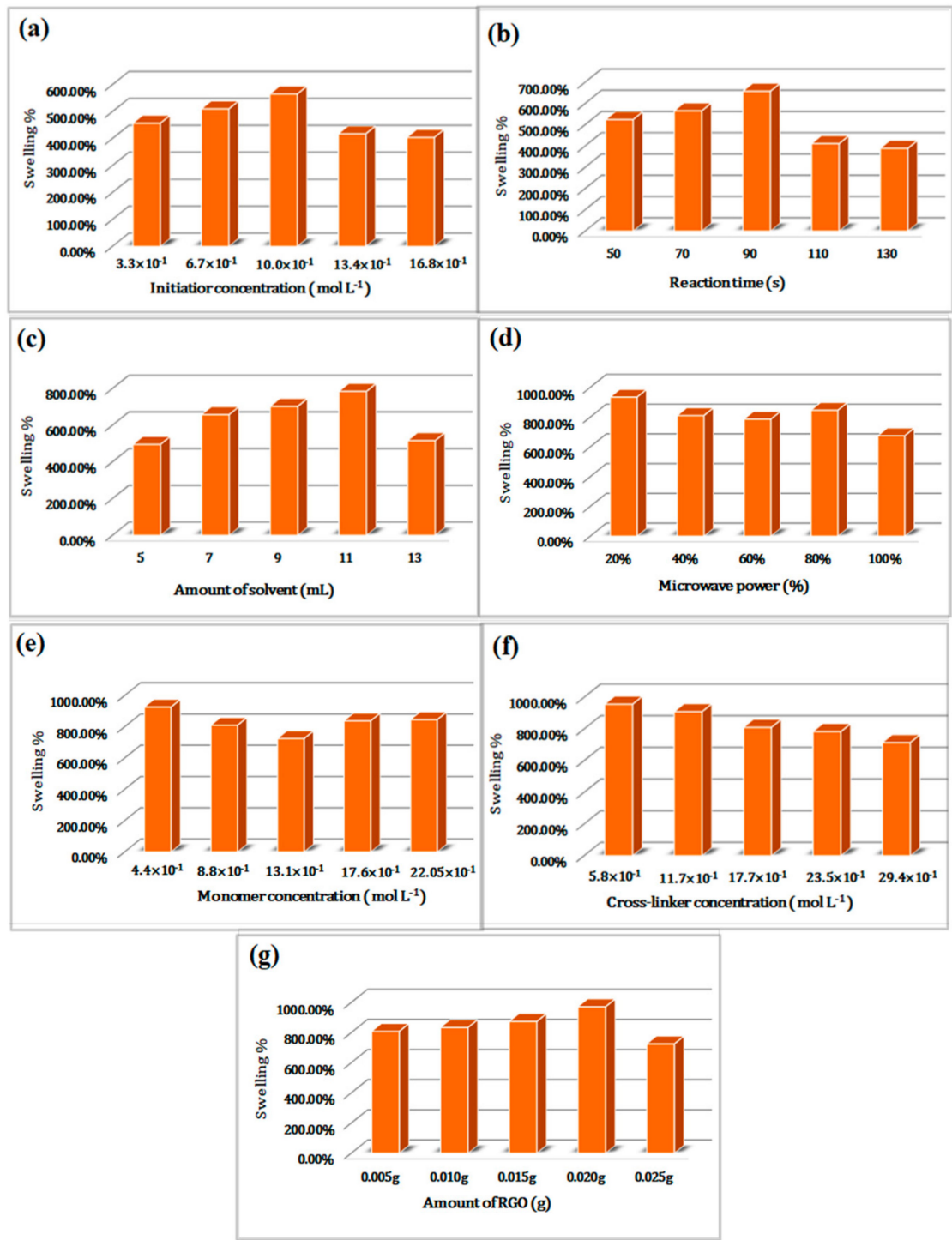

Figure 1. Effect of (a) initiator (KPS) concentration, (b) reaction time (s), (c) amount of solvent (mL), (d) microwave power (\%), (e) monomer (DMA) concentration, (f) cross-linker (NMBA) concentration and (g) amount of reduced graphene oxide (RGO) on gum tragacanth-cl- $N, N$-dimethylacrylamide hydrogel swelling. 


\subsubsection{Reaction Time}

The GT-cl-poly(DMA) hydrogel showed the highest swelling percentage (657.8\%) at $90 \mathrm{~s}$ (Figure 1b). The swelling percentage was decreased from $90 \mathrm{~s}$ to $130 \mathrm{~s}$, this might be due to the formation of excess branched chains that could inhibit the expansion of the polymer.

\subsubsection{Solvent}

The solvent volume was varied from $5 \mathrm{~mL}$ to $13 \mathrm{~mL}$ in the formation of GT-cl-poly(DMA) hydrogel (Figure 1c). The maximum swelling (784.4\%) was obtained at solvent volume of $11 \mathrm{~mL}$. At higher solvent volume beyond $11 \mathrm{~mL}$, the swelling percentage of GT-cl-poly(DMA) hydrogel was decreased, the excess solvent volume lowered the concentration of KPS, DMA and NMBA resulted in poor degree of polymerization.

\subsubsection{Microwave Power}

The swelling percentage was maximum at $20 \%$ of microwave power for GT-cl-poly(DMA) hydrogel (Figure 1d). The swelling percentage was lower at microwave power above $20 \%$. This was due to the formation of excess radical led to increase the homo-polymerization rate reaction. Hence, the microwave power was kept at $20 \%$ for further synthesis reaction of GT-cl-poly(DMA) hydrogel.

\subsubsection{Monomer (DMA) Concentration}

The swelling percentage was affected by concentration of monomer (DMA) used in the development of GT-cl-poly(DMA) hydrogel. The maximum swelling percentage was observed at $4.4 \times 10^{-1} \mathrm{~mol} \mathrm{~L}^{-1}$ of DMA concentration (Figure 1e). The increase in the concentration of DMA monomer from $4.4 \times 10^{-1} \mathrm{~mol} \mathrm{~L}^{-1}$ to $22.05 \times 10^{-1} \mathrm{~mol} \mathrm{~L}^{-1}$ led to decrease the swelling percentage due to the self cross-linking of DMA.

\subsubsection{Cross-Linker (NMBA)}

Figure $1 \mathrm{f}$ demonstrates the effect of NMBA concentration $\left(5.8 \times 10^{-1}-29.4 \times 10^{-1} \mathrm{~mol} \mathrm{~L}^{-1}\right)$ on the swelling percentage of GT-cl-poly(DMA) hydrogel. The recorded highest swelling percentage was $957.2 \%$ at NMBA concentration of $5.8 \times 10^{-1} \mathrm{~mol} \mathrm{~L}^{-1}$. Beyond $5.8 \times 10^{-1} \mathrm{~mol} \mathrm{~L}^{-1}$, the excess network was developed due to the more cross-linking points. Thus, the excess network led to decrease the available pores and swelling percentage of GT-cl-poly(DMA) hydrogel.

\subsubsection{RGO Loading}

Figure $1 \mathrm{~g}$ shows the influence of RGO loading on the swelling of GT-cl-poly(DMA) hydrogel. The rise in the amount of RGO from $0.005 \mathrm{~g}$ to $0.020 \mathrm{~g}$ was attributed to an increase in swelling percentage. This was due to an increase in hydrophilic group and surface area of GT-cl-poly(DMA) on the incorporation of RGO. Any further increase in RGO loading ( $>0.020 \mathrm{~g})$ was found to decrease the swelling percentage of GT-cl-poly(DMA) hydrogel. This might be attributed to the increased cross-linking density of composite hydrogel networks and the aggregations of excessive RGO in the hydrogel matrix.

\subsection{FTIR}

The FTIR graphs of samples are presented in Figure 2. In spectrum of RGO (Figure 2a), broadband of nearly $3358 \mathrm{~cm}^{-1}$ can be attributed to $-\mathrm{OH}$ stretching mode. The peak at $1421 \mathrm{~cm}^{-1}$ corresponds to the carboxylic acid and peak at $1625 \mathrm{~cm}^{-1}$ belongs to the $-\mathrm{C}=\mathrm{C}$ group in the aromatic rings. The peak at $1128 \mathrm{~cm}^{-1}$ is due to $-\mathrm{C}-\mathrm{O}$ stretching in the $\mathrm{C}-\mathrm{OH}$ functional groups of $\mathrm{RGO}$ [29]. The shifting of -C-O stretching from $1128 \mathrm{~cm}^{-1}$ to $1125 \mathrm{~cm}^{-1}$ in GT-cl-poly(DMA)/RGO hydrogel composite is related to the successful incorporation of RGO in GT-cl-poly(DMA) hydrogel. The bands at $1638 \mathrm{~cm}^{-1}$ and $1748 \mathrm{~cm}^{-1}$ correspond to asymmetric stretching of the carboxylate group and asymmetric stretching of 
$\mathrm{C}=\mathrm{O}$ in galacturonic acid respectively [30], peak at $1142 \mathrm{~cm}^{-1}$ ascribed to antisymmetric vibrations of $\mathrm{C}-\mathrm{O}-\mathrm{C}$ linkage in glycosidic groups [31]. The asymmetric stretching of $\mathrm{C}=\mathrm{O}$ shows shifting of peaks from $1748 \mathrm{~cm}^{-1}$ to $1750 \mathrm{~cm}^{-1}$ after the crosslinking of poly(DMA). The GT-cl-poly(DMA)/RGO hydrogel composite (Figure 2a) shows shift related to asymmetric stretching of $\mathrm{C}=\mathrm{O}$ from $1750 \mathrm{~cm}^{-1}$ to $1758 \mathrm{~cm}^{-1}$ suggesting interaction between RGO and GT-cl-poly(DMA) hydrogel. The peaks at $1608 \mathrm{~cm}^{-1}$ and $1410 \mathrm{~cm}^{-1}$ in GT-cl-poly(DMA) hydrogel ascribed to stretching vibrations of poly(DMA) amide group [32]. These stretching vibrations of poly(DMA) show peak shifting from $1608 \mathrm{~cm}^{-1}$ to $1612 \mathrm{~cm}^{-1}$ and from $1410 \mathrm{~cm}^{-1}$ to $1403 \mathrm{~cm}^{-1}$ in GT-cl-poly(DMA)/RGO hydrogel composite which confirms the changes in the structure of poly(DMA) after RGO incorporation. In GT-cl-poly(DMA)/RGO, the broadband of $\mathrm{O}-\mathrm{H}$ stretching vibration shifted from $3403 \mathrm{~cm}^{-1}$ to $3382 \mathrm{~cm}^{-1}$ which may be attributed to the RGO interaction with GT-cl-poly(DMA) through intermolecular hydrogen bonds. The peaks intensity of GT-cl-poly(DMA)/RGO hydrogel composite is slightly lower than the GT-cl-poly(DMA) hydrogel, which also confirms the RGO dispersion in GT-cl-poly(DMA)/RGO hydrogel composite. The absorption band at $2910 \mathrm{~cm}^{-1}$ was attributed to stretching vibrations of aliphatic $\mathrm{C}-\mathrm{H}$ [10]. Also, peaks at $1048 \mathrm{~cm}^{-1}$ and $1052 \mathrm{~cm}^{-1}$ in the spectra of hydrogels correspond to the $-\mathrm{C}-\mathrm{O}$ bending. After the adsorption of $\mathrm{Hg}^{2+}$ and $\mathrm{Cr}^{6+}$ on GT-cl-poly(DMA) hydrogel and GT-cl-poly(DMA)/RGO hydrogel composite, peak due to carboxylate groups was shifted from $1612 \mathrm{~cm}^{-1}$ to $1621 \mathrm{~cm}^{-1}$ and the intensity of the peaks decreases (Figure 2b). The peaks at $1410 \mathrm{~cm}^{-1}$ and $1048 \mathrm{~cm}^{-1}$ were shifted to $1403 \mathrm{~cm}^{-1}$ and $1061 \mathrm{~cm}^{-1}$ respectively, which was probably due to the interactions of metal ions to the active site of adsorbent. The peaks intensity of $\mathrm{Hg}^{2+}$ loaded GT-cl-poly(DMA) hydrogel and GT-cl-poly(DMA)/RGO hydrogel composite was lower than the $\mathrm{Cr}^{6+}$ loaded GT-cl-poly(DMA) hydrogel and GT-cl-poly(DMA)/RGO hydrogel composite, which supports higher $\mathrm{Hg}^{2+}$ adsorption than $\mathrm{Cr}^{6+}$ adsorption.
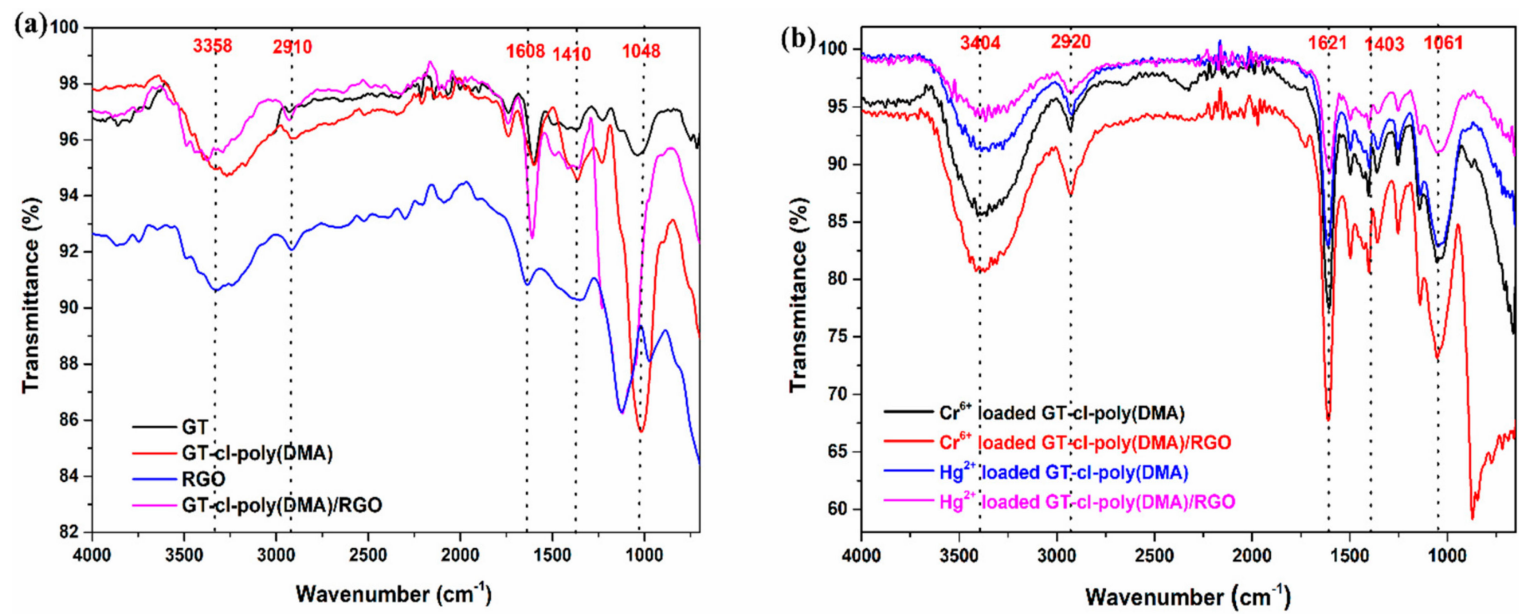

Figure 2. Fourier transform infrared of (a) gum tragacanth (GT), gum tragacanth-cl- $N, N$ dimethylacrylamide (GT-cl-poly(DMA)) hydrogel, RGO and reduced graphene oxide incorporated gum tragacanth-cl-N,N-dimethylacrylamide (GT-cl-poly(DMA)/RGO) hydrogel composite, $(\mathbf{b}) \mathrm{Hg}^{2+}$ and $\mathrm{Cr}^{6+}$ loaded GT-cl-poly(DMA) hydrogel and GT-cl-poly(DMA)/RGO hydrogel composite.

\section{4. $X R D$}

The XRD pattern of GT, gum tragacanth-cl- $N, N$-dimethylacrylamide hydrogel (GT-cl-poly(DMA)), RGO and reduced graphene oxide incorporated gum tragacanth-cl- $N, N$-dimethylacrylamide hydrogel composite (GT-cl-poly(DMA)/RGO) is shown in Figure 3. The RGO formation was confirmed by the characteristic peak at $2 \theta=24.3^{\circ}$ [33]. On applying Bragg's law, the calculated interlayer spacing of RGO was $0.367 \mathrm{~nm}$. Another peak of RGO at $2 \theta=43.6^{\circ}$ corresponded to the fingermark of graphite indicating the regeneration of graphitic onto RGO [34]. According to Scherrer's formula the calculated particle size of RGO at $2 \theta=24.3^{\circ}$ was $0.894 \mathrm{~nm}$. In the case of GT, the diffraction peak occurred 
at $2 \theta=22.9^{\circ}$ and $26.2^{\circ}$, exhibited semi-crystalline in nature [35]. The slight shifting of the peak at $2 \theta=26.6^{\circ}$ in XRD pattern of GT-cl-poly(DMA) hydrogel confirms the crosslinking of DMA with polysaccharide by destroying semi-crystalline structure into the amorphous structure. The broad peak in GT-cl-poly(DMA)/RGO hydrogel composite indicates the poor ordered arrangement of RGO in GT-cl-poly(DMA) hydrogel supported by SEM morphology.

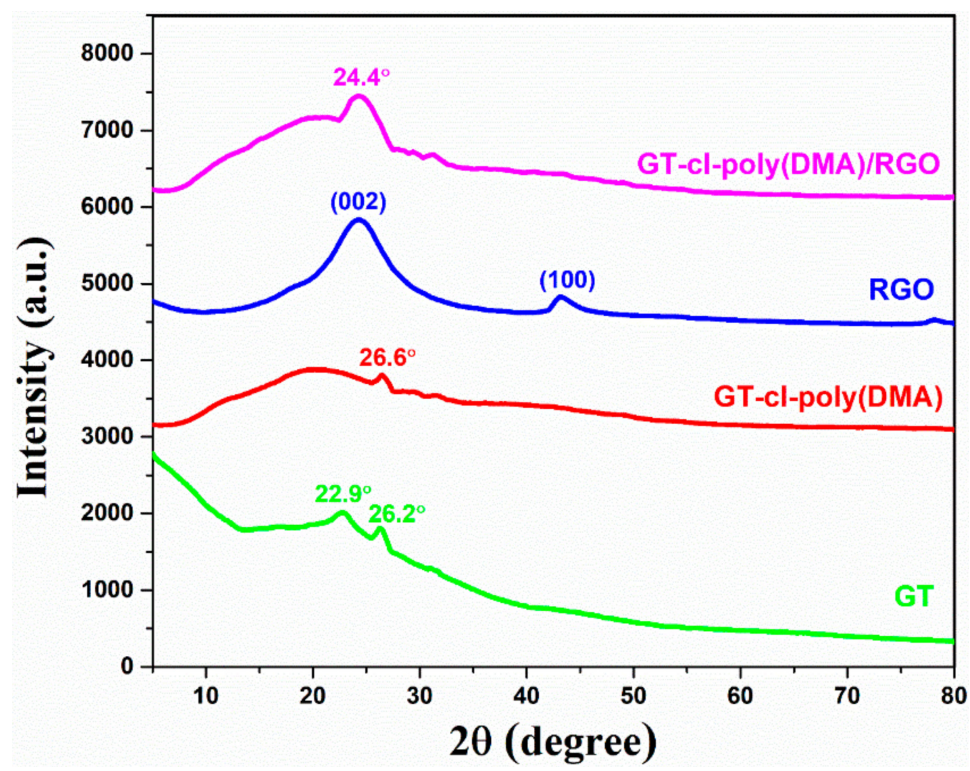

Figure 3. X-ray diffraction pattern for gum tragacanth (GT), gum tragacanth-cl- $N, N$-dimethylacrylamide (GT-cl-poly(DMA)) hydrogel, RGO and reduced graphene oxide incorporated gum tragacanth-cl-N,N-dimethylacrylamide (GT-cl-poly(DMA)/RGO) hydrogel composite.

\subsection{SEM}

Microscopic images of RGO, gum tragacanth-cl- $N, N$-dimethylacrylamide hydrogel and reduced graphene oxide incorporated gum tragacanth-cl- $\mathrm{N}, \mathrm{N}$-dimethylacrylamide hydrogel composite are shown in Figure 4. In RGO, Figure 4a shows the aggregated wrinkled structure, which means particles were closely associated. The RGO morphology showed the formation of agglomerated RGO with estimated average grain size of $20-25 \mathrm{~nm}$. Figure $4 \mathrm{~b}$ shows the distribution of certain bulges on a quite smooth, porous and compact surface of gum tragacanth-cl- $N, N$-dimethylacrylamide hydrogel. After the incorporation of RGO, reduced graphene oxide incorporated gum tragacanth-cl- $\mathrm{N}, \mathrm{N}$-dimethylacrylamide hydrogel composite showed (Figure $4 \mathrm{c}$ ) the rough and irregular surface with reduced size which was beneficial in fast adsorption of $\mathrm{Hg}^{2+}$ and $\mathrm{Cr}^{6+}$.

\subsection{EDS}

The elemental distribution of carbon, oxygen, nitrogen, mercury and chromium in hydrogel matrix was evaluated by EDS analysis and the spectra for $\mathrm{Hg}^{2+}$ adsorbed GT-cl-DMA hydrogel, $\mathrm{Hg}^{2+}$ adsorbed GT-cl-poly(DMA)/RGO hydrogel composite, $\mathrm{Cr}^{6+}$ adsorbed GT-cl-poly(DMA) and $\mathrm{Cr}^{6+}$ adsorbed GT-cl-poly(DMA)/RGO are presented in Figure 5. It is evident from the elemental analysis that $\mathrm{Hg}^{2+}$ and $\mathrm{Cr}^{6+}$ ions were successfully adsorbed by GT-cl-poly(DMA) and GT-cl-poly(DMA)/RGO. Importantly, the weight percentages of $\mathrm{Hg}^{2+}$ and $\mathrm{Cr}^{6+}$ ions were higher in the case of $\mathrm{Hg}^{2+}$ adsorbed GT-cl-poly(DMA)/RGO (6.68\%) (Figure 5b) and $\mathrm{Cr}^{6+}$ adsorbed GT-cl-poly(DMA)/RGO $(0.86 \%)$ (Figure $5 \mathrm{~d}$ ) than the $\mathrm{Hg}^{2+}$ adsorbed GT-cl-poly(DMA) $\left(1.20 \%\right.$ ) (Figure 5a) and $\mathrm{Cr}^{6+}$ adsorbed GT-cl-poly(DMA) (0.46\%) respectively (Figure 5c). Hence, GT-cl-poly(DMA)/RGO hydrogel composite showed better adsorption capability than GT-cl-poly(DMA) hydrogel. Also, the weight percentage of carbon is higher the in case of GT-cl-poly(DMA)/RGO hydrogel composite than the GT-cl-poly(DMA) hydrogel which confirmed the successful dispersion of RGO in GT-cl-poly(DMA) hydrogel matrix. 

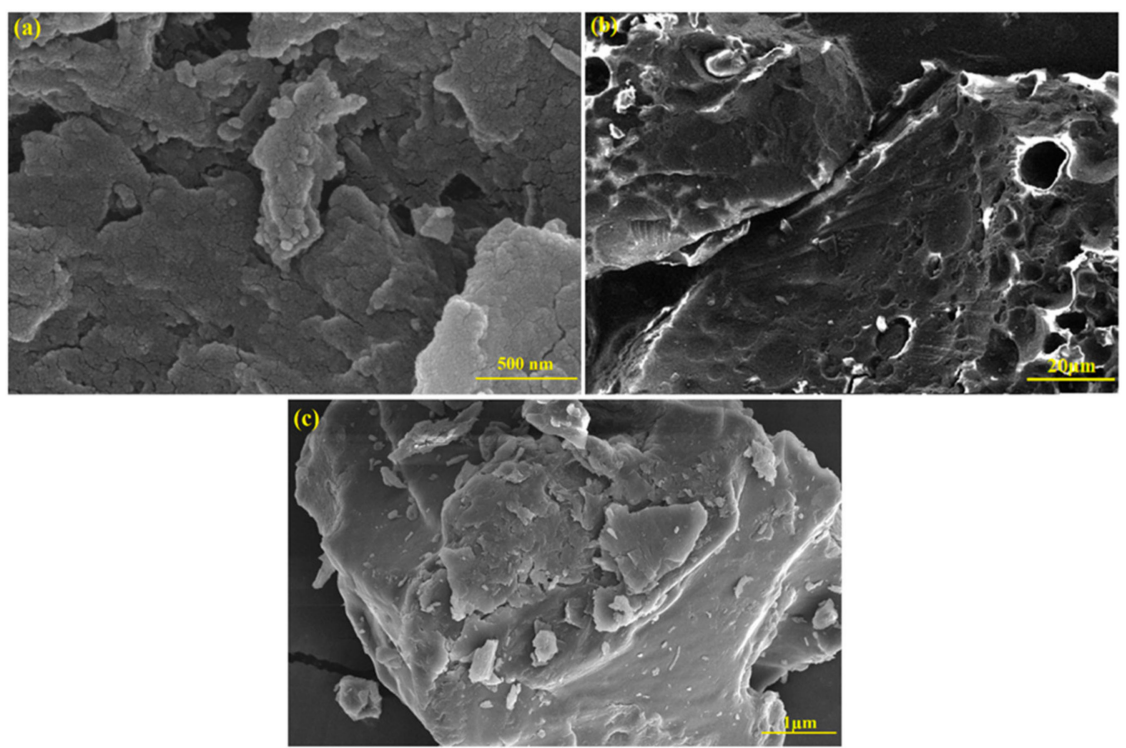

Figure 4. Scanning electron microscope images of (a) RGO, (b) gum tragacanth-cl- $N, N-$ dimethylacrylamide hydrogel and (c) reduced graphene oxide incorporated gum tragacanth-cl- $N, N$-dimethylacrylamide hydrogel composite.
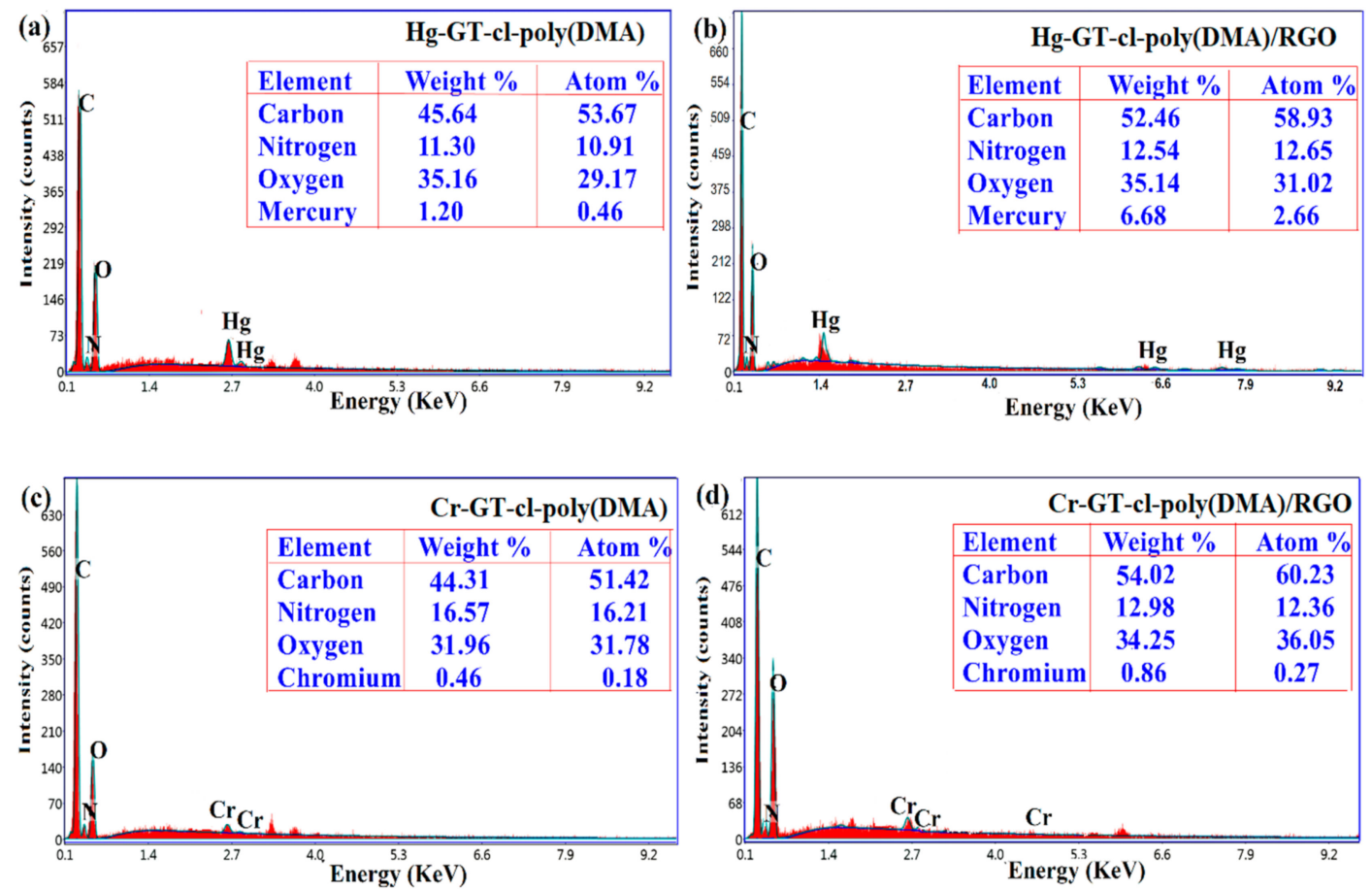

Figure 5. Energy dispersive X-ray spectroscopy and elemental weight percentage for (a) $\mathrm{Hg}^{2+}$ adsorbed gum tragacanth-cl-N,N-dimethylacrylamide (GT-cl-poly(DMA)) hydrogel, (b) $\mathrm{Hg}^{2+}$ adsorbed reduced graphene oxide incorporated gum tragacanth-cl- $N, N$-dimethylacrylamide (GT-cl-poly(DMA)/RGO) hydrogel composite, (c) $\mathrm{Cr}^{6+}$ adsorbed gum tragacanth-cl- $N, N$-dimethylacrylamide (GT-clpoly(DMA)) hydrogel and (d) $\mathrm{Cr}^{6+}$ adsorbed reduced graphene oxide incorporated gum tragacanth-cl-N,N-dimethylacrylamide (GT-cl-poly(DMA)/RGO) hydrogel composite. 
3.7. Application of Gum Tragacanth-cl-N,N-dimethylacrylamide (GT-cl-poly(DMA)) Hydrogel and Reduced Graphene Oxide Incorporated Gum Tragacanth-cl-N,N-dimethylacrylamide (GT-cl-poly(DMA)/RGO) Hydrogel Composite for Removal of $\mathrm{Hg}^{2+}$ and $\mathrm{Cr}^{6+}$

\subsubsection{Influence of RGO Loading on the Removal of $\mathrm{Hg}^{2+}$ and $\mathrm{Cr}^{6+}$}

In the GT-cl-poly(DMA) hydrogel matrix, different quantities of RGO $(0.005 \mathrm{~g}, 0.01 \mathrm{~g}, 0.015 \mathrm{~g}, 0.02 \mathrm{~g}$ and $0.025 \mathrm{~g}$ ) were incorporated to study the effect RGO loading on metal ions removal. The adsorption percentages for without RGO were $70.6 \%$ and $20.4 \%$ for $\mathrm{Hg}^{2+}$ and $\mathrm{Cr}^{6+}$ respectively. The adsorption percentages for $\mathrm{Hg}^{2+}$ (Figure 6a) and $\mathrm{Cr}^{6+}$ (Figure 6b) ions were enhanced on raising the concentration of RGO from $0.005 \mathrm{~g}$ to $0.020 \mathrm{~g}$. The RGO contains carboxylic groups which boost interactions with metal ions resulting in high percentage adsorption [30]. The removal efficiency of $\mathrm{Hg}^{2+}$ and $\mathrm{Cr}^{6+} \mathrm{was}^{2}$ $90.7 \%$ and $38.4 \%$ at RGO loading of $0.020 \mathrm{~g}$. The development of tough three-dimensional networks was responsible for the decrease in adsorption percentage at higher RGO loading $(>0.020)$. Therefore, $0.020 \mathrm{~g}$ was the optimized dose of RGO in the formation of GT-cl-poly(DMA)/RGO for removal of $\mathrm{Hg}^{2+}$ and $\mathrm{Cr}^{6+}$.
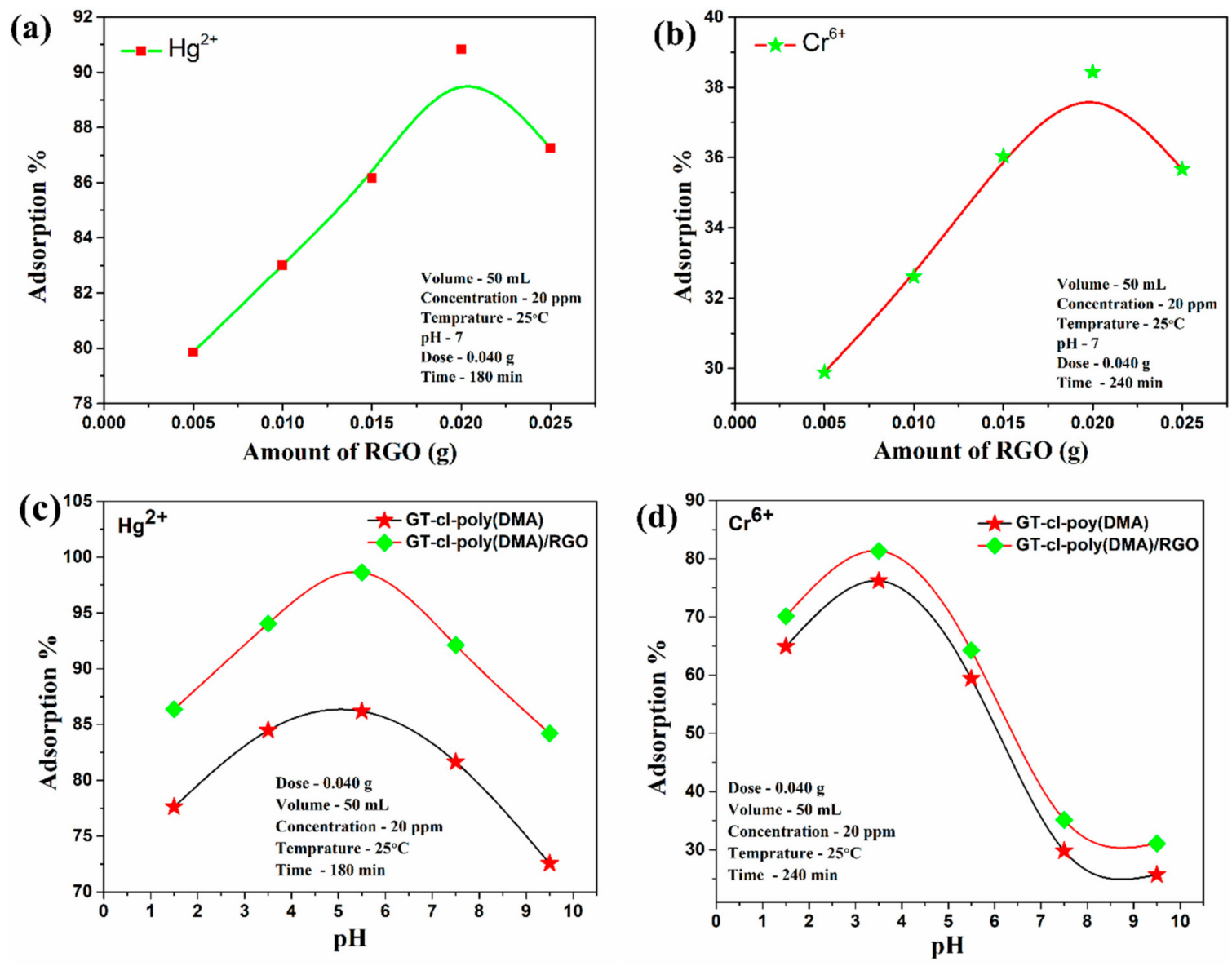

Figure 6. Cont. 

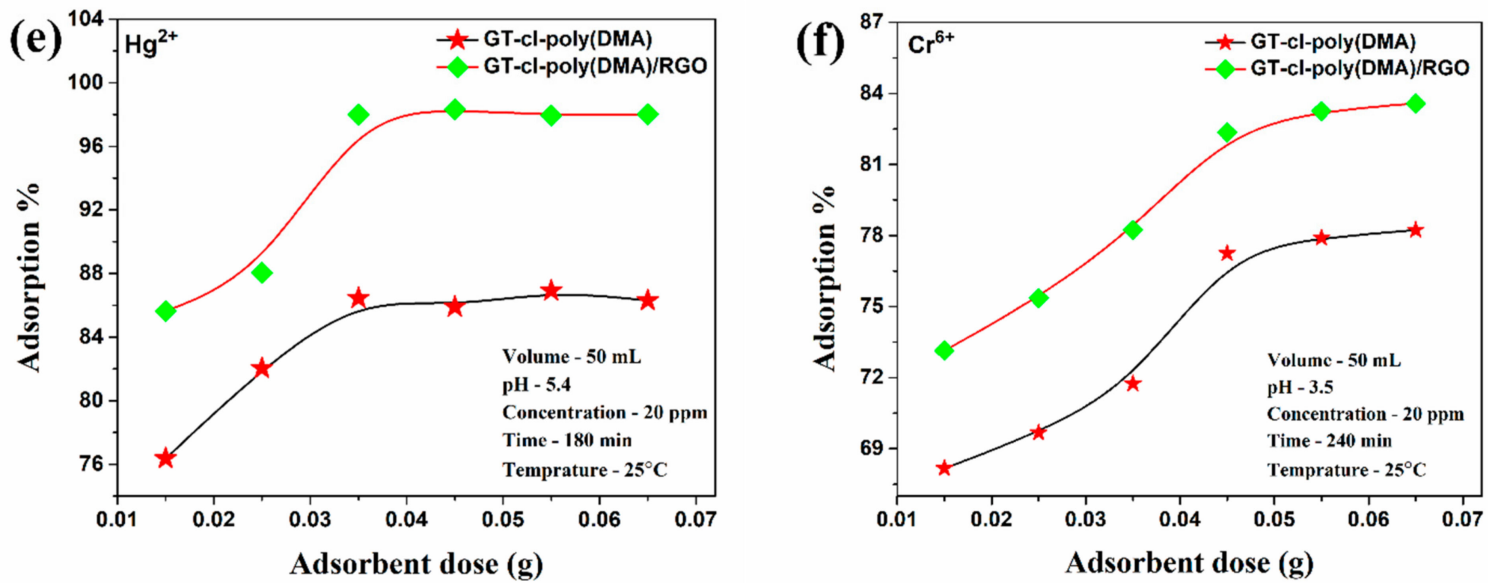

Figure 6. Influence of (a) RGO loading on $\mathrm{Hg}^{2+}$ adsorption (b) RGO loading on $\mathrm{Cr}^{6+}$ adsorption, (c) $\mathrm{pH}$ on adsorption of $\mathrm{Hg}^{2+}$, (d) $\mathrm{pH}$ on adsorption of $\mathrm{Cr}^{6+}$, (e) adsorbent dose on adsorption of $\mathrm{Hg}^{2+}$, (f) adsorbent dose on adsorption of $\mathrm{Cr}^{6+}$. Adsorbent: gum tragacanth-cl- $N, N-$ dimethylacrylamide (GT-cl-poly(DMA)) hydrogel and reduced graphene oxide incorporated gum tragacanth-cl-N,N-dimethylacrylamide (GT-cl-poly(DMA)/RGO) hydrogel composite.

3.7.2. Influence of $\mathrm{pH}$ on Removal of $\mathrm{Hg}^{2+}$ and $\mathrm{Cr}^{6+}$ by GT-cl-poly(DMA) Hydrogel and GT-cl-poly (DMA)/RGO Hydrogel Composite

The impact of $\mathrm{pH}$ on adsorption percentage for $\mathrm{Hg}^{2+}$ (Figure 6c) and $\mathrm{Cr}^{6+}$ (Figure 6d) by gum tragacanth-cl- $N, N$-dimethylacrylamide (GT-cl-poly(DMA)) hydrogel and reduced graphene oxide incorporated gum tragacanth-cl- $N, N$-dimethylacrylamide (GT-cl-poly(DMA)/RGO) hydrogel composite are shown in Figure 6. The removal percentage of $\mathrm{Hg}^{2+}$ was first increased from $\mathrm{pH} 1.5$ (77.6\% for GT-cl-poly(DMA), 86.3\% for GT-cl-poly(DMA)/RGO) to 5.5 (86.1\% for GT-cl-poly(DMA), $97.6 \%$ for GT-cl-poly(DMA)/RGO) and then decreased from pH $5.5(86.1 \%, 97.6 \%)$ to $9.5(72.5 \%$, $84.2 \%$ ). The reported highest removal efficiencies for $\mathrm{Hg}^{2+}$ were $86.1 \%$ and $97.6 \%$ by GT-cl-poly(DMA) hydrogel and GT-cl-poly(DMA)/RGO) hydrogel composite respectively at $5.5 \mathrm{pH}$. At low $\mathrm{pH}$, the concentration of $\mathrm{H}^{+}$ions was high which could compete with $\mathrm{Hg}^{2+}$ on GT-cl-poly(DMA)/RGO surface resulting in poor binding of $\mathrm{Hg}^{2+}$ [36]. However, high $\mathrm{pH}$ was responsible for the decrease in the concentration of $\mathrm{H}^{+}$ions in the solution and improves the binding potential of $\mathrm{Hg}^{2+}$ ions to the surface of GT-cl-poly(DMA)/RGO) (Scheme 2a). Hence adsorption of $\mathrm{Hg}^{2+}$ was increased from $\mathrm{pH} 1.1$ to 5.5 . The dominant species were $\mathrm{Hg}(\mathrm{OH})_{2}$ and $\mathrm{HgCl}_{4}{ }^{2-}$ [37] at $\mathrm{pH}$ above 5.5. The electrostatic repulsion among $\mathrm{Hg}(\mathrm{OH})_{2}$ or $\mathrm{HgCl}_{4}{ }^{2-}$ [38] and negatively charged GT-cl-poly(DMA)/RGO) was responsible for low $\mathrm{Hg}^{2+}$ adsorption percentage at $\mathrm{pH}$ above 5.5.

In the case of $\mathrm{Cr}^{6+}$, the recorded maximum adsorption percentages were $76.1 \%$ and 81.5\% (Figure 6d) for GT-cl-poly(DMA) hydrogel and GT-cl-poly(DMA)/RGO hydrogel composite correspondingly at $\mathrm{pH}$ 3.5. The dominant $\mathrm{Cr}^{6+}$ species [39] are as: $\mathrm{H}_{2} \mathrm{CrO}_{4}(\mathrm{pH}<3.5), \mathrm{HCrO}_{4}^{-}(\mathrm{pH}<7)$, $\mathrm{CrO}_{4}^{2-}(\mathrm{pH}>7)$. The $\mathrm{Cr}^{6+}$ ions were exists in solution as negatively charged $\mathrm{HCrO}_{4}^{-}$at $\mathrm{pH}$ 3.5. Therefore, electrostatic attraction of $\mathrm{HCrO}_{4}^{-}$[40] took place at $\mathrm{pH} 3.5$ with protonated positively charged group of GT-cl-poly(DMA)/RGO) (Scheme 2b). Hence, $\mathrm{Cr}^{6+}$ exhibited maximum adsorption percentage at $3.5 \mathrm{pH}$. At $\mathrm{pH}<3.5$, electrostatic attraction for adsorption was reduced due to the dominance of $\mathrm{H}_{2} \mathrm{CrO}_{4}$. Also, with increasing $\mathrm{pH}$ from 3.5 to 7 , the protonated group on GT-cl-poly(DMA)/RGO decreases which reduces the electrostatic attraction. At $\mathrm{pH}>7$, electrostatic repulsion between dominant $\mathrm{CrO}_{4}^{2-}$ species [40] and deprotonated GT-cl-poly(DMA)/RGO was attributed to low $\mathrm{Cr}^{6+}$ adsorption. 


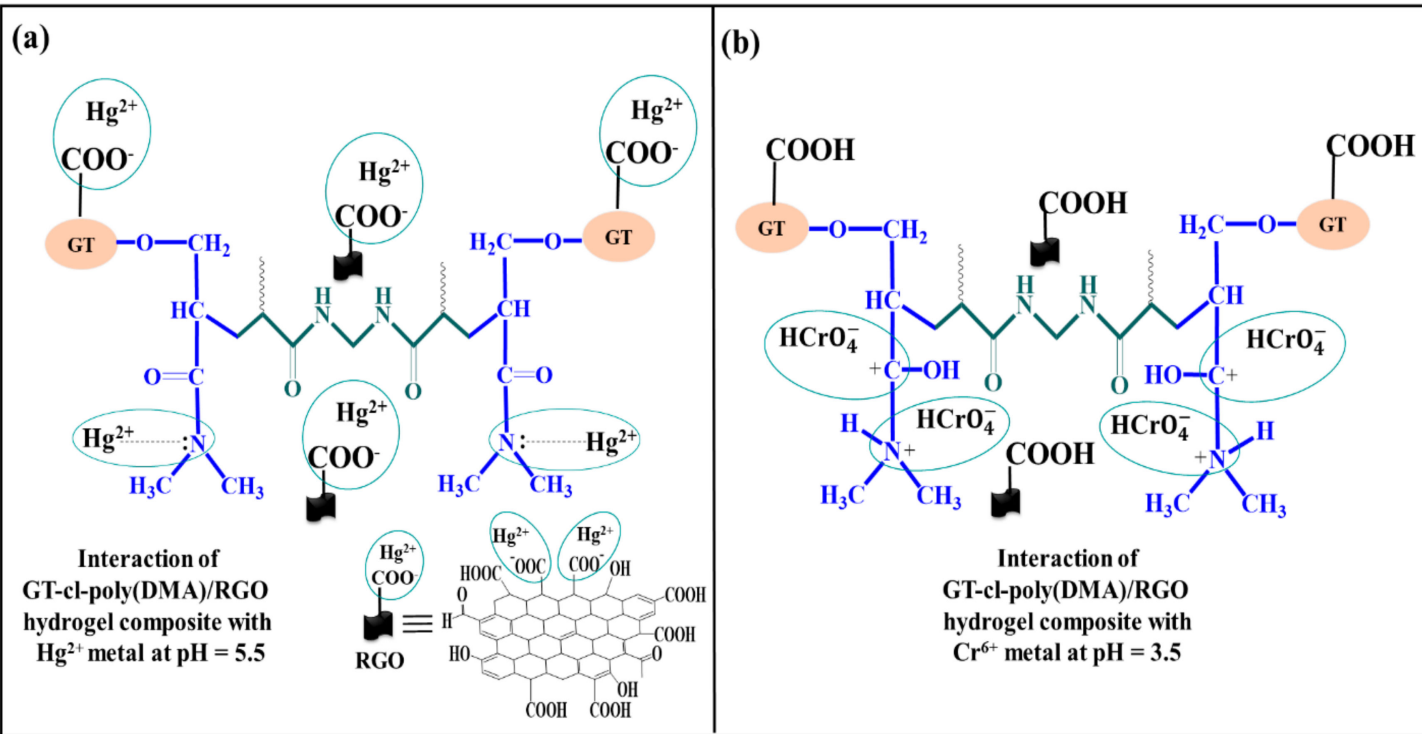

Scheme 2. Possible interactions of $(\mathbf{a}) \mathrm{Hg}^{2+}$ at $\mathrm{pH} 5.5$ and (b) $\mathrm{Cr}^{6+}$ at $\mathrm{pH} 3.5$ with GT-cl-poly(DMA)/RGO hydrogel composite adsorbent.

3.7.3. Influence of GT-cl-poly(DMA) Hydrogel and GT-cl-poly(DMA)/RGO Hydrogel Composite Dose for Removal of $\mathrm{Hg}^{2+}$ and $\mathrm{Cr}^{6+}$

The effect of adsorbents dosages $(0.015-0.065 \mathrm{~g})$ on the removal of metal ions are represented in Figure $6 \mathrm{e}, \mathrm{f}$. The adsorption percentage was increased by increasing the adsorbent dosage. This was due to the existence of more adsorption sites with enhanced dose of adsorbent. The removal efficiencies of $\mathrm{Hg}^{2+}$ were found to be $86.4 \%$ and $98.4 \%$ by GT-cl-poly(DMA) hydrogel and GT-cl-poly(DMA)/RGO hydrogel composite correspondingly at dose of $0.035 \mathrm{~g}$. The reported $\mathrm{Cr}^{6+}$ ion removal percentages were $77.2 \%$ and $82.3 \%$ by using GT-cl-poly(DMA) hydrogel and GT-cl-poly(DMA)/RGO hydrogel composite respectively at optimized dose of $0.045 \mathrm{~g}$. Thus, $0.035 \mathrm{~g}\left(\right.$ for $\mathrm{Hg}^{2+}$ ) and $0.045 \mathrm{~g}\left(\right.$ for $\left.\mathrm{Cr}^{6+}\right)$ were the ideal doses used for experiments.

\subsection{Adsorption Kinetics}

The pseudo first-order rate equation is given as:

$$
\log \left(q_{e}-q_{t}\right)=\log q_{e}-\frac{K_{1}}{2.303} t
$$

where, $\mathrm{q}_{\mathrm{e}}$ and $\mathrm{q}_{\mathrm{t}}$ are the adsorption capacity at equilibrium $\left(\mathrm{mg} \mathrm{g}^{-1}\right)$ and time $\mathrm{t}$ respectively and $\mathrm{K}_{1}$ is the pseudo first order kinetics rate constant.

The pseudo second-order rate equation is given as:

$$
\frac{\mathrm{t}}{\mathrm{q}_{\mathrm{t}}}=\frac{1}{\mathrm{~K}_{2} \mathrm{q}_{\mathrm{e}}^{2}}+\frac{\mathrm{t}}{\mathrm{q}_{\mathrm{e}}}
$$

where $\mathrm{K}_{2}$ is the pseudo second-order kinetics rate constant.

The removal mechanism for $\mathrm{Hg}^{2+}$ and $\mathrm{Cr}^{6+}$ by GT-cl-poly(DMA) and GT-cl-poly(DMA)/RGO were solved by different kinetic models as given in Equations (3) and (4). The parameters (pseudo-first-order: $\mathrm{R}^{2}, \mathrm{~K}_{1}, \mathrm{q}_{\mathrm{e}}$ ) were calculated from Figure $7 \mathrm{a}, \mathrm{b}$ (Table 4). The parameters (pseudo-second-order: $\mathrm{K}_{2}, \mathrm{q}_{\mathrm{e}}$ ) and correlation coefficient $\left(\mathrm{R}^{2}\right)$ were calculated from Figure $7 \mathrm{c}, \mathrm{d}$ (Table 4). The higher $\mathrm{R}^{2}$ values for the pseudo-second-order kinetic model supports $\mathrm{Hg}^{2+}$ and $\mathrm{Cr}^{6+}$ ions adsorption onto GT-cl-poly(DMA) hydrogel and GT-cl-poly(DMA)/RGO hydrogel composite through the pseudo-second-order kinetic model. 

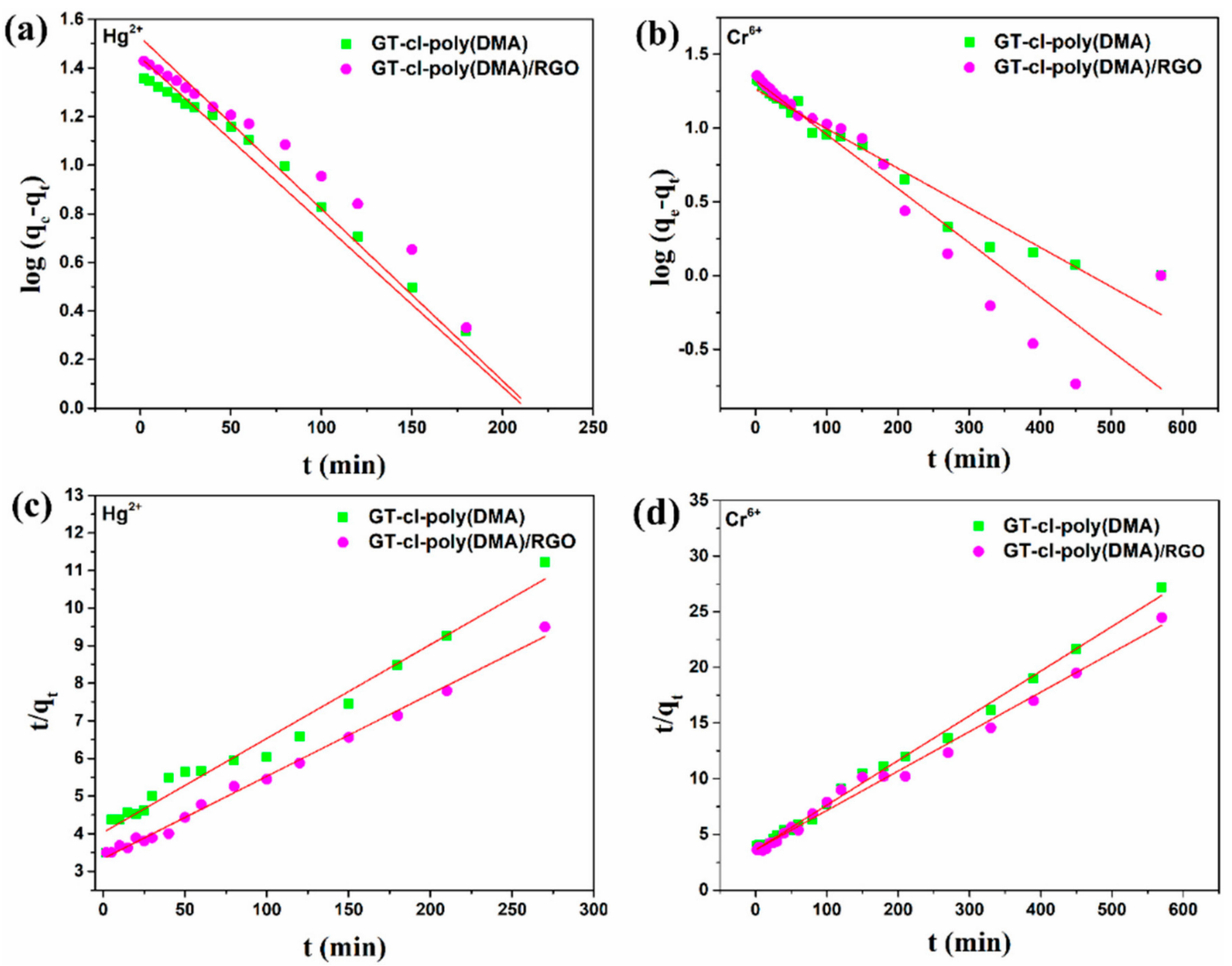

Figure 7. Pseudo first order for (a) $\mathrm{Hg}^{2+}$ and (b) $\mathrm{Cr}^{6+}$, pseudo second order for (c) $\mathrm{Hg}^{2+}$ and (d) $\mathrm{Cr}^{6+}$. (Experimental conditions for $\mathrm{Hg}^{2+}$ : adsorbent dose- $0.035 \mathrm{~g}, \mathrm{pH}-5.5$, metal ion concentration-20 ppm, $\mathrm{rpm}=200$ and for $\mathrm{Cr}^{6+}$ : adsorbent dose $-0.045 \mathrm{~g}, \mathrm{pH}-3.5$, metal ion concentration-20 ppm, rpm $=200$ ).

Table 4. Kinetics model parameters for $\mathrm{Hg}^{2+}$ and $\mathrm{Cr}^{6+}$ removal by GT-cl-poly(DMA) hydrogel and GT-cl-poly(DMA)/RGO hydrogel composite.

\begin{tabular}{cccccc}
\hline \multirow{2}{*}{ Kinetic Model } & Parameters & \multicolumn{2}{c}{ GT-cl-poly(DMA) } & \multicolumn{2}{c}{ GT-cl-poly(DMA)/RGO } \\
& $\mathbf{H g}^{\mathbf{2 +}}$ & $\mathbf{C r}^{\mathbf{6 +}}$ & $\mathbf{H g}^{\mathbf{2 +}}$ & $\mathbf{C r}^{\mathbf{6 +}}$ \\
\hline \multirow{3}{*}{ Pseudo-first-order } & $\mathrm{R}^{2}$ & 0.946 & 0.931 & 0.909 & 0.863 \\
kinetics & $\mathrm{qe}_{\mathrm{e}}(\mathrm{cal})$ & 25.7 & 19.0 & 33.5 & 21.0 \\
& $\mathrm{q}_{\mathrm{e}}(\mathrm{exp})$ & 28.2 & 22.6 & 40.8 & 25.9 \\
& $\mathrm{k}_{1}$ & 0.011 & 0.008 & 0.016 & 0.006 \\
Pseudo-second-order & $\mathrm{R}^{2}$ & 0.989 & 0.995 & 0.994 & 0.989 \\
kinetics & $\mathrm{q}_{\mathrm{e}}(\mathrm{cal})$ & 29.4 & 25 & 45.8 & 28.3 \\
& $\mathrm{q}_{\mathrm{e}}(\mathrm{exp})$ & 28.2 & 22.6 & 40.8 & 25.9 \\
& $\mathrm{k}_{2}$ & 5.90 & 4.42 & 1.42 & 3.44 \\
\hline
\end{tabular}

\subsection{Adsorption Isotherms}

The Langmuir model is expressed according to Equation (5) as:

$$
\frac{C_{e}}{q_{e}}=\frac{1}{q_{m} b}+\frac{C_{e}}{q_{m}}
$$

where $C_{e}$ is the equilibrium concentration of metal ions solution, $q_{e}$ is the amount of equilibrium adsorbed metal ions, $\mathrm{q}_{\mathrm{m}}$ is maximum adsorption capacity and $\mathrm{b}$ is the Langmuir isotherm constant. The separation factor $R_{L}$ of Langmuir isotherm was examined by using Equation (6) as:

$$
\mathrm{R}_{\mathrm{L}}=\frac{1}{1+\mathrm{b} \times \mathrm{C}_{\mathrm{o}}}
$$


where $C_{o}$ represent the initial concentration of metal ions. The $R_{L}$ values show the nature of adsorption i.e. irreversible $\left(R_{L}=0\right)$, linear $\left(R_{L}=1\right)$, unfavorable $\left(R_{L}>1\right)$ and favorable $\left(0<R_{L}<1\right)$. The Freundlich isotherm model is given by Equation (7) as:

$$
\ln \mathrm{q}_{\mathrm{e}}=\ln \mathrm{K}_{\mathrm{F}}+\frac{1}{\mathrm{n}} \ln \mathrm{C}_{\mathrm{e}}
$$

where $\mathrm{K}_{\mathrm{F}}$ and $\mathrm{n}$ are Freundlich constants and indicate the adsorption capacity and adsorption intensity of adsorbent respectively.

The interaction between adsorbent (GT-cl-poly(DMA) hydrogel and GT-cl-poly(DMA)/RGO hydrogel composite) and adsorbate $\left(\mathrm{Hg}^{2+}\right.$ and $\left.\mathrm{Cr}^{6+}\right)$ was explained through isotherms model Equations (5) and (7). The Langmuir parameters were calculated from the graph between $C_{e} / q_{e}$ and $C_{e}$ (Figure 8a-d) and presented in Table 5. The Freundlich parameters were determined from the graph of $\ln q_{e}$ vs $\ln C_{e}$ (Figure $9 a-d$ ) and depicted in Table 5. For the Langmuir isotherm, the higher $\mathrm{R}^{2}$ suggests that the Langmuir isotherm was best suited for the removal of $\mathrm{Hg}^{2+}$ and $\mathrm{Cr}^{6+}$ ions on GT-cl-poly(DMA) hydrogel and GT-cl-poly(DMA)/RGO hydrogel composite. For $\mathrm{Hg}^{2+}$, GT-cl-poly(DMA) and GT-cl-poly(DMA)/RGO showed higher removal capacity of $625 \mathrm{mg} \mathrm{g}^{-1}$ and $666.6 \mathrm{mg} \mathrm{g}^{-1}$ respectively. Similarly, for $\mathrm{Cr}^{6+}$, the maximum reported removal capacities were $401.6 \mathrm{mg} \mathrm{g}^{-1}$ and $473.9 \mathrm{mg} \mathrm{g}^{-1}$ by GT-cl-poly(DMA) hydrogel and GT-cl-poly(DMA)/RGO hydrogel composite respectively.
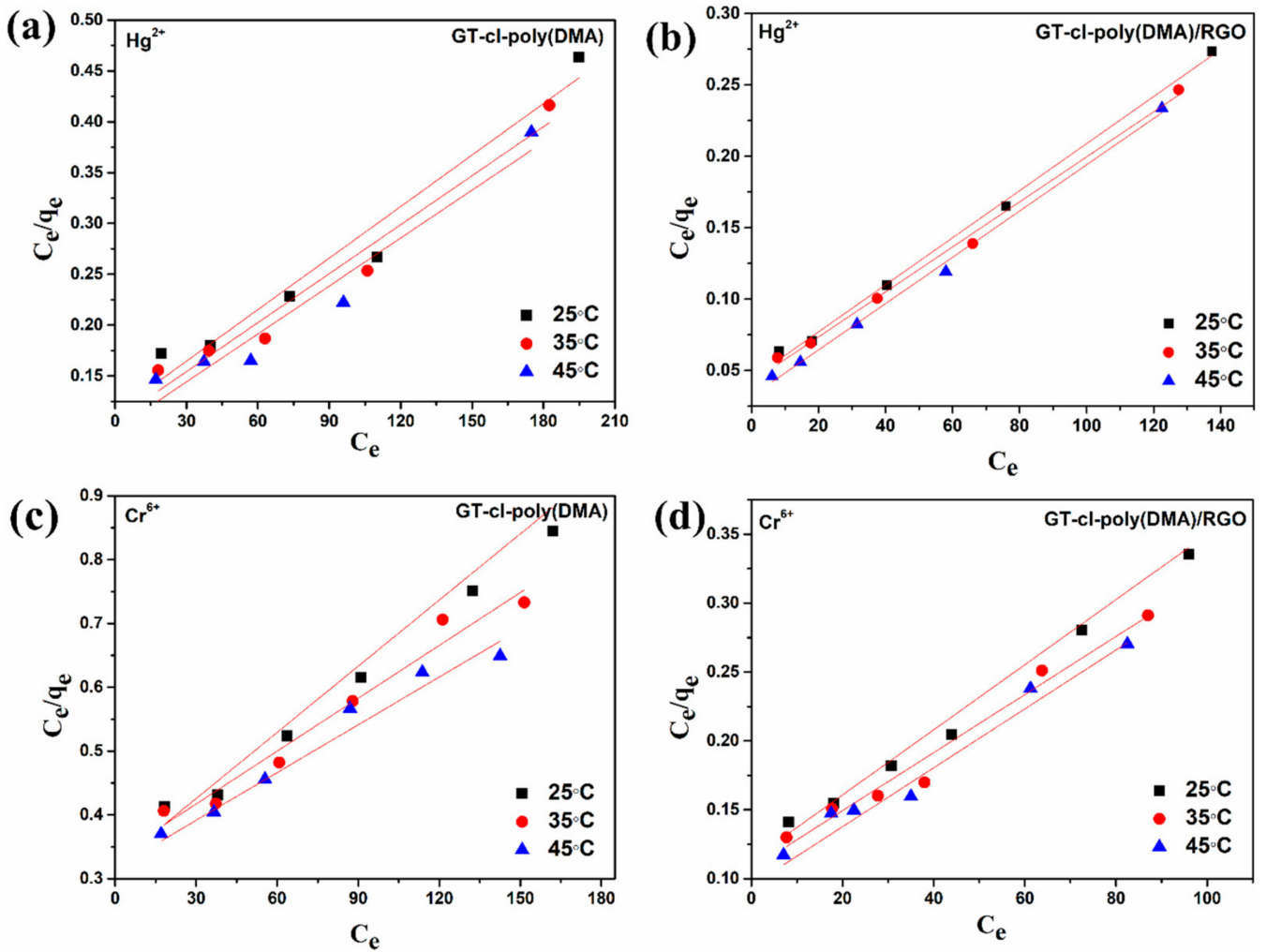

Figure 8. Langmuir isotherm model for $\mathrm{Hg}^{2+}$ adsorption by (a) gum tragacanth-cl- $N, N-$ dimethylacrylamide (GT-cl-poly(DMA)) hydrogel (b) reduced graphene oxide incorporated gum tragacanth-cl- $N, N$-dimethylacrylamide (GT-cl-poly(DMA)/RGO) hydrogel composite, Langmuir isotherm model for $\mathrm{Cr}^{6+}$ adsorption by (c) gum tragacanth-cl- $N, N$-dimethylacrylamide (GT-cl-poly(DMA)) hydrogel (d) reduced graphene oxide incorporated gum tragacanth-cl- $N, N-$ dimethylacrylamide (GT-cl-poly(DMA)/RGO) hydrogel composite. (Experimental conditions for $\mathrm{Hg}^{2+}$ : adsorbent dose $-0.035 \mathrm{~g}, \mathrm{pH}-5.5$, metal ion concentration-20-300 ppm, rpm $=200$ and for $\mathrm{Cr}^{6+}$ : adsorbent dose $-0.045 \mathrm{~g}, \mathrm{pH}-3.5$, metal ion concentration-20-500 ppm, rpm $=200$ ). 
(a)

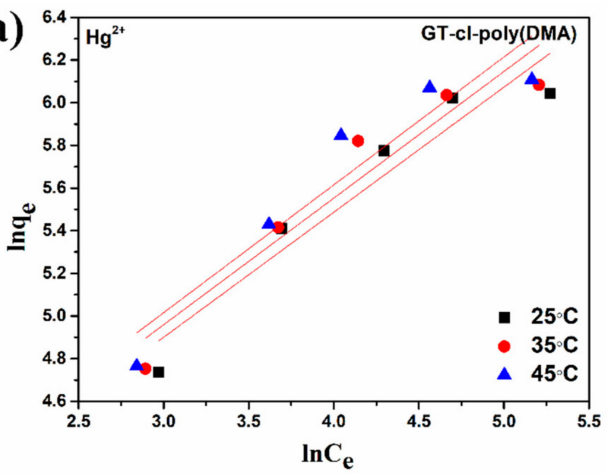

(c)

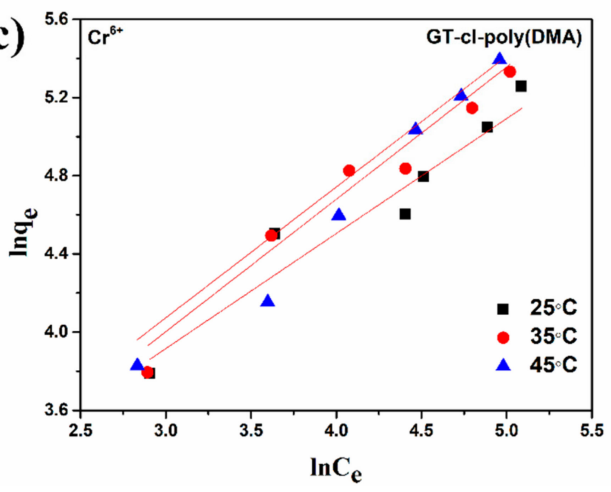

(b)

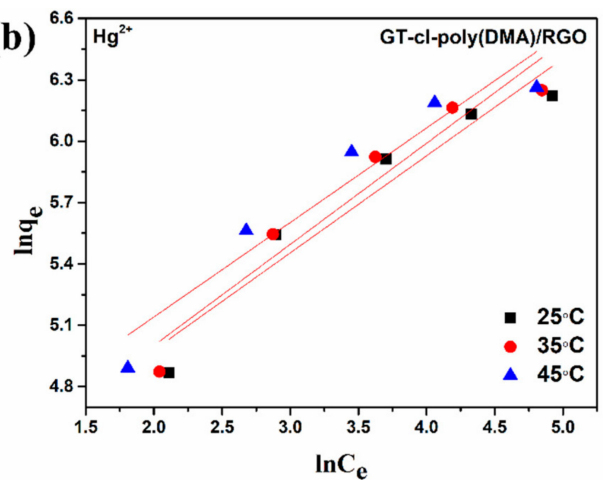

(d)

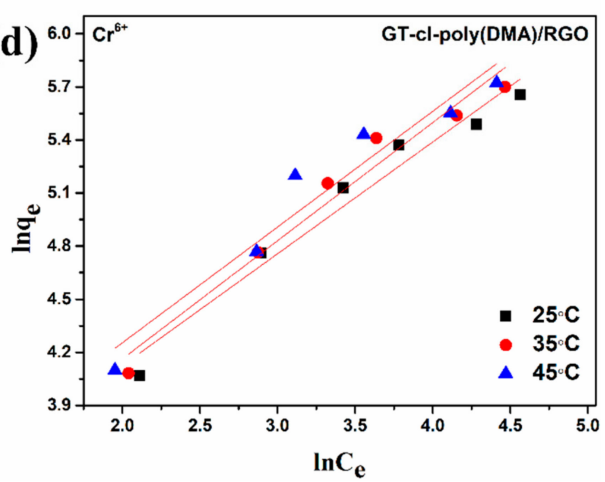

Figure 9. Freundlich isotherm model for $\mathrm{Hg}^{2+}$ adsorption by (a) gum tragacanth-cl- $N, N-$ dimethylacrylamide (GT-cl-poly(DMA)) hydrogel (b) reduced graphene oxide incorporated gum tragacanth-cl- $N, N$-dimethylacrylamide (GT-cl-poly(DMA)/RGO) hydrogel composite, Freundlich isotherm model for $\mathrm{Cr}^{6+}$ adsorption by (c) gum tragacanth-cl- $N, N$-dimethylacrylamide (GT-cl-poly(DMA)) hydrogel (d) reduced graphene oxide incorporated gum tragacanth-cl- $N, N$ dimethylacrylamide (GT-cl-poly(DMA)/RGO) hydrogel composite, (Experimental conditions for $\mathrm{Hg}^{2+}$ : adsorbent dose $-0.035 \mathrm{~g}, \mathrm{pH}-5.5$, metal ion concentration-20-300 ppm, $\mathrm{rpm}=200$ and for $\mathrm{Cr}^{6+}$ : adsorbent dose $-0.045 \mathrm{~g}, \mathrm{pH}-3.5$, metal ion concentration-20-500 ppm, rpm $=200$ ).

Table 5. Isotherm model parameters for $\mathrm{Hg}^{2+}$ and $\mathrm{Cr}^{6+}$ adsorption by GT-cl-poly(DMA) hydrogel and GT-cl-poly(DMA)/RGO hydrogel composite.

\begin{tabular}{|c|c|c|c|c|c|c|}
\hline \multirow{2}{*}{$\begin{array}{l}\text { Isotherm } \\
\text { Models }\end{array}$} & \multirow{2}{*}{ Temperature } & \multirow{2}{*}{ Parameters } & \multicolumn{2}{|c|}{ GT-cl-poly(DMA) } & \multicolumn{2}{|c|}{ GT-cl-poly(DMA)/RGO } \\
\hline & & & $\mathrm{Hg}^{2+}$ & $\mathrm{Cr}^{6+}$ & $\mathrm{Hg}^{2+}$ & $\mathrm{Cr}^{6+}$ \\
\hline \multirow{12}{*}{ Langmuir } & \multirow{4}{*}{$25^{\circ} \mathrm{C}$} & $\mathrm{q}_{\mathrm{m}}\left(\mathrm{mg} \mathrm{g}^{-1}\right)$ & 591.7 & 289.8 & 628.9 & 423.7 \\
\hline & & $\mathrm{b}\left(\mathrm{L} \mathrm{mg}^{-1}\right)$ & 0.014 & 0.010 & 0.036 & 0.020 \\
\hline & & $\mathrm{R}_{\mathrm{L}}$ & $0.405-0.121$ & $0.839-0.370$ & $0.217-0.052$ & $0.856-0.339$ \\
\hline & & $\mathrm{R}^{2}$ & 0.987 & 0.964 & 0.996 & 0.989 \\
\hline & \multirow{4}{*}{$35^{\circ} \mathrm{C}$} & $\mathrm{q}_{\mathrm{m}}\left(\mathrm{mg} \mathrm{g}^{-1}\right)$ & 621.1 & 362.3 & 662.2 & 467.2 \\
\hline & & $\mathrm{b}\left(\mathrm{L} \mathrm{mg}^{-1}\right)$ & 0.015 & 0.008 & 0.035 & 0.019 \\
\hline & & $\mathrm{R}_{\mathrm{L}}$ & $0.400-0.119$ & $0.874-0.452$ & $0.220-0.054$ & $0.869-0.371$ \\
\hline & & $\mathrm{R}^{2}$ & 0.960 & 0.962 & 0.994 & 0.989 \\
\hline & \multirow{4}{*}{$45^{\circ} \mathrm{C}$} & $\mathrm{q}_{\mathrm{m}}\left(\mathrm{mg} \mathrm{g}^{-1}\right)$ & 625 & 401.6 & 666.6 & 473.9 \\
\hline & & $\mathrm{b}\left(\mathrm{L} \mathrm{mg}^{-1}\right)$ & 0.016 & 0.007 & 0.046 & 0.022 \\
\hline & & $\mathrm{R}_{\mathrm{L}}$ & $0.385-0.112$ & $0.887-0.438$ & $0.167-0.039$ & $0.864-0.353$ \\
\hline & & $\mathrm{R}^{2}$ & 0.963 & 0.956 & 0.995 & 0.9623 \\
\hline \multirow{9}{*}{ Freundlich } & \multirow{3}{*}{$25^{\circ} \mathrm{C}$} & $\mathrm{K}_{\mathrm{F}}\left(\mathrm{mg} \mathrm{g}^{-1}\right)$ & 1.144 & 0.765 & 1.393 & 1.05 \\
\hline & & $\mathrm{n}$ & 1.72 & 1.70 & 2.12 & 1.58 \\
\hline & & $\mathrm{R}^{2}$ & 0.889 & 0.898 & 0.905 & 0.955 \\
\hline & \multirow{3}{*}{$35^{\circ} \mathrm{C}$} & $\mathrm{K}_{\mathrm{F}}\left(\mathrm{mg} \mathrm{g}^{-1}\right)$ & 1.156 & 0.679 & 1.389 & 1.038 \\
\hline & & $\mathrm{N}$ & 1.69 & 1.47 & 2.04 & 1.52 \\
\hline & & $R^{2}$ & 0.891 & 0.895 & 0.914 & 0.955 \\
\hline & \multirow{3}{*}{$45^{\circ} \mathrm{C}$} & $\mathrm{K}_{\mathrm{F}}\left(\mathrm{mg} \mathrm{g}^{-1}\right)$ & 1.168 & 0.726 & 1.438 & 1.080 \\
\hline & & $\mathrm{n}$ & 1.66 & 1.49 & 2.17 & 1.53 \\
\hline & & $\mathrm{R}^{2}$ & 0.868 & 0.876 & 0.898 & 0.924 \\
\hline
\end{tabular}




\subsection{Relationship between the Adsorption and Swelling}

For the investigation of the correlation between the swelling of GT-cl-poly(DMA)/RGO hydrogel composite and adsorption of the $\mathrm{Hg}^{2+}$ and $\mathrm{Cr}^{6+}$ onto GT-cl-poly(DMA)/RGO hydrogel composite, the adsorption percentage was determined using aqueous metal solution $\left(20 \mathrm{mg} \mathrm{L}^{-1}\right)$ and the swelling experiments were performed in distilled water. The relationship between the adsorption values versus swelling values is presented in Figure 10. It is clear from Figure 10 that the adsorption percentage is directly proportional to the swelling percentage of the adsorbent. The adsorption percentages for $\mathrm{Hg}^{2+}$ and $\mathrm{Cr}^{6+}$ were increased from $78.9 \%$ to $90.7 \%$ and $29.8 \%$ to $38.4 \%$ respectively when the swelling percentage of GT-cl-poly(DMA)/RGO rise from $834.6 \%$ to $971.9 \%$.

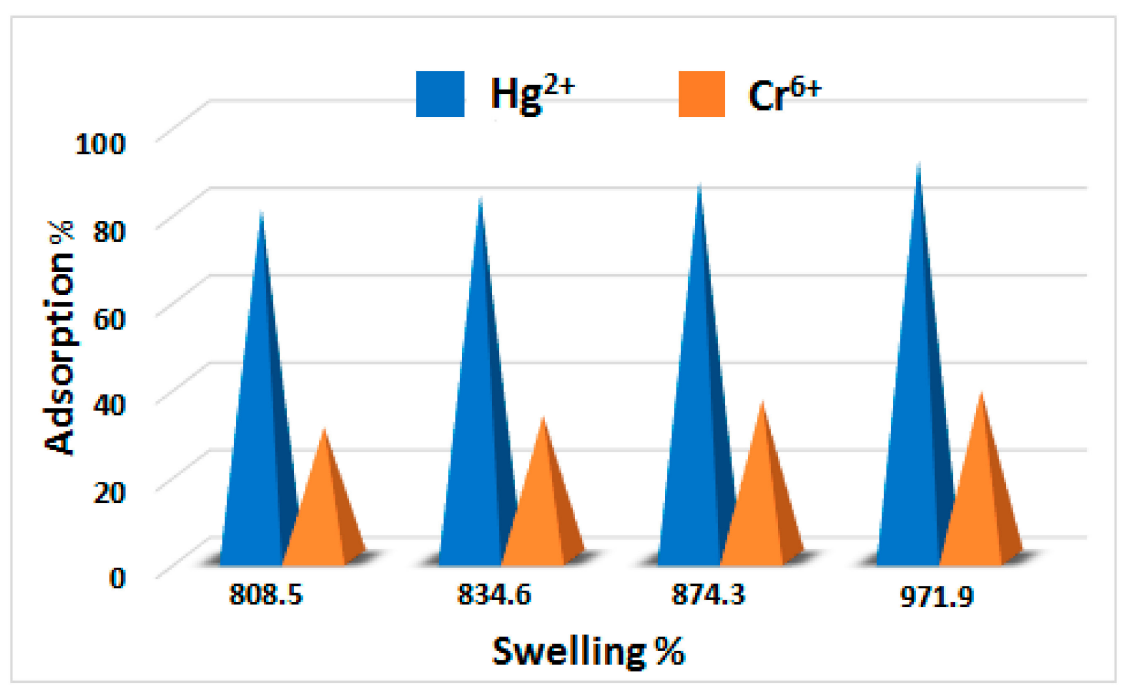

Figure 10. Adsorption percentage and swelling percentage of reduced graphene oxide incorporated gum tragacanth-cl-N,N-dimethylacrylamide (GT-cl-poly(DMA)/RGO) hydrogel composite.

\subsection{Adsorption-Desorption Study}

For an ideal adsorbent, ability for regeneration without considerable loss of removal percentage is of paramount importance. The five cycles of adsorption-desorption and their effects on percentage adsorption are presented in Figure 11. The $\mathrm{Hg}^{2+}$ ions adsorption percentages were $83.4 \%$ (1st cycle), $80.9 \%$ (2nd cycle), $78.4 \%$ (3rd cycle), 75\% (4th cycle), 73.6\% (5th cycle) and $94.1 \%$ (1st cycle), $92.7 \%$ (2nd cycle), 89.8\% (3rd cycle), 87.9\% (4th cycle), 85.5\% (5th cycle) for GT-cl-poly(DMA) hydrogel and GT-cl-poly(DMA)/RGO hydrogel composite respectively (Figure 11a). For $\mathrm{Cr}^{6+}$, GT-cl-poly(DMA) and GT-cl-poly(DMA)/RGO exhibited 77.2\% (1st cycle), 74.7\% (2nd cycle), 71\% (3rd cycle), 68.4\% (4th cycle), 66.3\% (5th cycle) and $82.3 \%$ (1st cycle), 80.1\% (2nd cycle), 78.5\% (3rd cycle), 76.9\% (4th cycle), $73.1 \%$ (5th cycle) respectively (Figure 11b). Hence, the synthesized GT-cl-poly(DMA) hydrogel and GT-cl-poly(DMA)/RGO hydrogel composite can be effectively reused for up to five cycles, which leads to reduction in cost. 

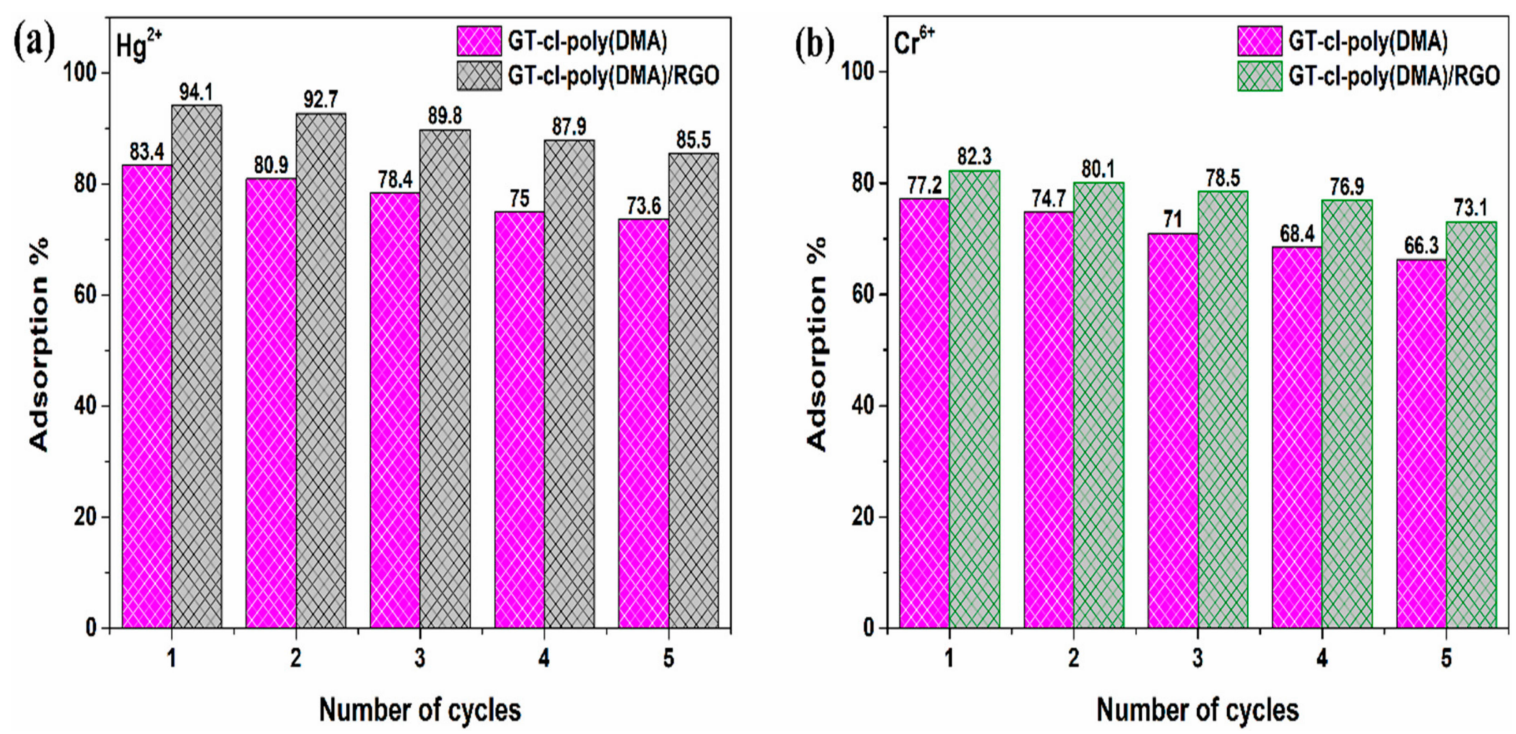

Figure 11. Recycling ability of gum tragacanth-cl- $N, N$-dimethylacrylamide (GT-cl-poly(DMA)) hydrogel and reduced graphene oxide incorporated gum tragacanth-cl- $N, N$-dimethylacrylamide (GT-cl-poly(DMA)/RGO) hydrogel composite for the removal of (a) $\mathrm{Hg}^{2+}$ and (b) $\mathrm{Cr}^{6+}$ metal ions up to five cycles.

\section{Conclusions}

We developed novel reduced graphene oxide incorporated gum tragacanth-cl- $N, N$ dimethylacrylamide (GT-cl-poly(DMA)/RGO) hydrogel composite as reusable adsorbent for $\mathrm{Hg}^{2+}$ and $\mathrm{Cr}^{6+}$ ions. The reported maximum swelling percentage was $971.9 \%$ for reduced graphene oxide incorporated gum tragacanth-cl- $\mathrm{N}, \mathrm{N}$-dimethylacrylamide hydrogel composite at optimized synthesis conditions (KPS concentration: $10.0 \times 10^{-1} \mathrm{~mol} \mathrm{~L}^{-1}$, solvent: $11 \mathrm{~mL}$, reaction time: $90 \mathrm{~s}$, microwave power: $20 \%$, DMA concentration: $4.4 \times 10^{-1} \mathrm{~mol} \mathrm{~L}^{-1}$, NMBA concentration: $5.8 \times 10^{-1} \mathrm{~mol} \mathrm{~L}^{-1}$ and amount of RGO: $0.020 \mathrm{~g}$ ). The adsorption efficiencies of $99 \%$ and $82 \%$ were reported for $\mathrm{Hg}^{2+}$ and $\mathrm{Cr}^{6+}$ by using GT-cl-poly(DMA)/RGO hydrogel composite at optimized adsorption conditions (for $\mathrm{Hg}^{2+}, \mathrm{pH}$ : 5.5, adsorbent dose: $0.035 \mathrm{~g}$, RGO loading: $0.020 \mathrm{~g}$, $\mathrm{Hg}^{2+}$ concentration: $20 \mathrm{ppm}, \mathrm{Hg}^{2+}$ volume: $50 \mathrm{~mL}$, time: $270 \mathrm{~min}$, temperature: $25^{\circ} \mathrm{C}$ and for $\mathrm{Cr}^{6+}, \mathrm{pH}: 3.5$, adsorbent dose: $0.045 \mathrm{~g}$, RGO loading: $0.020 \mathrm{~g}$, $\mathrm{Cr}^{6+}$ concentration: $20 \mathrm{ppm}, \mathrm{Cr}^{6+}$ volume: $50 \mathrm{~mL}$, time: $570 \mathrm{~min}$, temperature: $25^{\circ} \mathrm{C}$ ). The $\mathrm{Q}_{\max }$ of $\mathrm{Hg}^{2+}$ and $\mathrm{Cr}^{6+}$ onto reduced graphene oxide incorporated gum tragacanth-cl- $N, N$-dimethylacrylamide hydrogel composite were $666.6 \mathrm{mg} \mathrm{g}^{-1}$ and $473.9 \mathrm{mg} \mathrm{g}^{-1}$ correspondingly, which were higher than the $\mathrm{Q}_{\max }$ of gum tragacanth-cl- $\mathrm{N}, \mathrm{N}$-dimethylacrylamide hydrogel $\left(\mathrm{Hg}^{2+}=625 \mathrm{mg} \mathrm{g}^{-1}, \mathrm{Cr}^{6+}=401.6 \mathrm{mg}\right.$ $\left.\mathrm{g}^{-1}\right)$. The $\mathrm{Hg}^{2+}$ and $\mathrm{Cr}^{6+}$ adsorption were better depicted through pseudo-second-order and Langmuir isotherm. The gum tragacanth-cl- $\mathrm{N}, \mathrm{N}$-dimethylacrylamide and reduced graphene oxide incorporated gum tragacanth-cl- $N, N$-dimethylacrylamide adsorbents can be effectively reused for up to five cycles for adsorption of $\mathrm{Hg}^{2+}$ and $\mathrm{Cr}^{6+}$ ions. Thus, developed adsorbents are highly efficient in heavy metal ion adsorption and can be exploited for environmental remediation application.

Author Contributions: Experiments, B.S.; original draft writing, B.S., S.T.; data analysis, B.S., S.T.; writing, review and editing, S.T., V.K.T., D.T., H.Y.N.; supervision, S.T., V.K.T. All authors have read and agreed to the published version of the manuscript.

Funding: This research received no external funding.

Conflicts of Interest: The authors declare no conflict of interest. 


\section{References}

1. Siddiqui, E.; Pandey, J. Assessment of heavy metal pollution in water and surface sediment and evaluation of ecological risks associated with sediment contamination in the Ganga River: A basin-scale study. Environ. Sci. Pollut. Res. 2019, 26, 10926-10940. [CrossRef] [PubMed]

2. Thakur, S.; Sharma, B.; Verma, A.; Chaudhary, J.; Tamulevicius, S.; Thakur, V.K. Recent approaches in guar gum hydrogel synthesis for water purification. Int. J. Polym. Anal. Chem. 2018, 23, 621-632. [CrossRef]

3. Thakur, S.; Sharma, B.; Verma, A.; Chaudhary, J.; Tamulevicius, S.; Thakur, V.K. Recent progress in sodium alginate based sustainable hydrogels for environmental applications. J. Clean. Prod. 2018, 198, 143-159. [CrossRef]

4. Hussain, I.; Sayed, S.M.; Fu, G. Facile and cost-effective synthesis of glycogen-based conductive hydrogels with extremely flexible, excellent self-healing and tunable mechanical properties. Int. J. Biol. Macromol. 2018, 118, 1463-1469. [CrossRef]

5. Chaudhary, J.; Thakur, S.; Sharma, M.; Gupta, V.K.; Thakur, V.K. Development of Biodegradable Agar-Agar/Gelatin-Based Superabsorbent Hydrogel as an Efficient Moisture-Retaining Agent. Biomolecules 2020, 10, 939. [CrossRef]

6. Nazarzadeh, E.Z.; Makvandi, P.; Tay, F.R. Recent progress in the industrial and biomedical applications of tragacanth gum: A review. Carbohydr. Polym. 2019, 212, 450-467. [CrossRef] [PubMed]

7. Ates, B.; Koytepe, S.; Ulu, A.; Gurses, C.; Thakur, V.K. Chemistry, Structures, and Advanced Applications of Nanocomposites from Biorenewable Resources. Chem. Rev. 2020. [CrossRef] [PubMed]

8. Mohammadinejad, R.; Maleki, H.; Larrañeta, E.; Fajardo, A.R.; Nik, A.B.; Shavandi, A.; Sheikhi, A.; Ghorbanpour, M.; Farokhi, M.; Govindh, P. Status and future scope of plant-based green hydrogels in biomedical engineering. Appl. Mat. Today 2019, 16, 213-246. [CrossRef]

9. Nejatian, M.; Abbasi, S.; Azarikia, F. Gum Tragacanth: Structure, characteristics and applications in foods. Int. J. Biol. Macromol. 2020, 160, 846-860. [CrossRef]

10. Mallakpour, S.; Abdolmaleki, A.; Tabesh, F. Ultrasonic-assisted manufacturing of new hydrogel nanocomposite biosorbent containing calcium carbonate nanoparticles and tragacanth gum for removal of heavy metal. Ultrason. Sonochem. 2018, 41, 572-581. [CrossRef]

11. Moghaddam, R.H.; Dadfarnia, S.; Shabani, A.M.H.; Tavakol, M. Synthesis of composite hydrogel of glutamic acid, gum tragacanth, and anionic polyacrylamide by electron beam irradiation for uranium (VI) removal from aqueous samples: Equilibrium, kinetics, and thermodynamic studies. Carbohydr. Polym. 2019, 206, 352-361. [CrossRef] [PubMed]

12. Guex, L.G.; Sacchi, B.; Peuvot, K.F.; Andersson, R.L.; Pourrahimi, A.M.; Ström, V.; Farris, S.; Olsson, R.T. Experimental review: Chemical reduction of graphene oxide (GO) to reduced graphene oxide (rGO) by aqueous chemistry. Nanoscale 2017, 9, 9562-9571. [CrossRef] [PubMed]

13. Peng, W.; Li, H.; Liu, Y.; Song, S. A review on heavy metal ions adsorption from water by graphene oxide and its composites. J. Mol. Liq. 2017, 230, 496-504. [CrossRef]

14. Yu, P.; Wang, H.-Q.; Bao, R.-Y.; Liu, Z.; Yang, W.; Xie, B.-H.; Yang, M.-B. Self-assembled sponge-like chitosan/reduced graphene oxide/montmorillonite composite hydrogels without cross-linking of chitosan for effective Cr (VI) sorption. ACS Sustain. Chem. Eng. 2017, 5, 1557-1566. [CrossRef]

15. Zhuang, Y.-T.; Zhang, X.; Wang, D.-H.; Yu, Y.-L.; Wang, J.-H. Three-dimensional molybdenum disulfide/graphene hydrogel with tunable heterointerfaces for high selective $\mathrm{Hg}$ (II) scavenging. J. Colloid Interf. Sci. 2018, 514, 715-722. [CrossRef]

16. Kim, M.Y.; Seo, H.; Lee, T.G. Removal of $\mathrm{Hg}$ (II) ions from aqueous solution by poly (allylamine-co-methacrylamide-co-dimethylthiourea). J. Ind. Eng. Chem. 2020, 84, 82-86. [CrossRef]

17. Zhang, M.; Ma, J.; Xiao, Y.; Zhang, C.; Wang, Q.; Zheng, W. Preparation sulfhydryl functionalized paramagnetic Ni0. 25Zn0. 75Fe2O4 microspheres for separating $\mathrm{Pb}$ (II) and $\mathrm{Hg}$ (II) ions from aqueous solution. Colloids Surf. A 2020, 586, 124205. [CrossRef]

18. Li, B.; Li, M.; Zhang, J.; Pan, Y.; Huang, Z.; Xiao, H. Adsorption of Hg (II) ions from aqueous solution by diethylenetriaminepentaacetic acid-modified cellulose. Int. J. Biol. Macromol. 2019, 122, 149-156. [CrossRef]

19. Monier, M.; Abdel-Latif, D.A. Preparation of cross-linked magnetic chitosan-phenylthiourea resin for adsorption of $\mathrm{Hg}$ (II), Cd (II) and Zn (II) ions from aqueous solutions. J. Hazard. Mater. 2012, 209, 240-249. [CrossRef] 
20. Li, S.-S.; Wang, X.-L.; An, Q.-D.; Xiao, Z.-Y.; Zhai, S.-R.; Cui, L.; Li, Z.-C. Upon designing carboxyl methylcellulose and chitosan-derived nanostructured sorbents for efficient removal of Cd (II) and Cr (VI) from water. Int. J. Biol. Macromol. 2020, 143, 640-650. [CrossRef]

21. Zhao, L.; Zhao, Y.; Yang, B.; Teng, H. Application of Carboxymethyl Cellulose-Stabilized Sulfidated Nano Zerovalent Iron for Removal of Cr (VI) in Simulated Groundwater. Water Air Soil Pollut. 2019, 230, 113. [CrossRef]

22. Espinoza-Sánchez, M.A.; Arévalo-Niño, K.; Quintero-Zapata, I.; Castro-González, I.; Almaguer-Cantú, V. $\mathrm{Cr}(\mathrm{VI})$ adsorption from aqueous solution by fungal bioremediation based using Rhizopus sp. J. Environ. Manage. 2019, 251, 109595. [CrossRef] [PubMed]

23. Dong, L.; Jin, Y.; Song, T.; Liang, J.; Bai, X.; Yu, S.; Teng, C.; Wang, X.; Qu, J.; Huang, X. Removal of Cr (VI) by surfactant modified Auricularia auricula spent substrate: Biosorption condition and mechanism. Environ. Sci. Pollut. Res. 2017, 24, 17626-17641. [CrossRef] [PubMed]

24. Sood, S.; Gupta, V.K.; Agarwal, S.; Dev, K.; Pathania, D. Controlled release of antibiotic amoxicillin drug using carboxymethyl cellulose-cl-poly (lactic acid-co-itaconic acid) hydrogel. Intern. J. Biol. Macromol. 2017, 101, 612-620. [CrossRef]

25. Pathania, D.; Verma, C.; Negi, P.; Tyagi, I.; Asif, M.; Kumar, N.S.; Al-Ghurabi, E.H.; Agarwal, S.; Gupta, V.K. Novel nanohydrogel based on itaconic acid grafted tragacanth gum for controlled release of ampicillin. Carbohydr. Polym. 2018, 196, 262-271. [CrossRef]

26. Wang, Z.; Zhao, Z.; KhaN, N.R.; Hua, Z.; Huo, J.; Li, Y. Microwave assisted chitosan-polyethylene glycol hydrogel membrane synthesis of curcumin for open incision wound healing. Pharmazie 2020, 75, 118-123.

27. Kaur, S.; Jindal, R.; Kaur Bhatia, J. Synthesis and RSM-CCD optimization of microwave-induced green interpenetrating network hydrogel adsorbent based on gum copal for selective removal of malachite green from waste water. Polym. Eng. Sci. 2018, 58, 2293-2303. [CrossRef]

28. Verma, A.; Thakur, S.; Mamba, G.; Gupta, R.K.; Thakur, P.; Thakur, V.K. Graphite modified sodium alginate hydrogel composite for efficient removal of malachite green dye. Inter. J. Biol. Macromol. 2020, 148, 1130-1139. [CrossRef]

29. Makhado, E.; Pandey, S.; Ramontja, J. Microwave assisted synthesis of xanthan gum-cl-poly(acrylic acid) based-reduced graphene oxide hydrogel composite for adsorption of methylene blue and methyl violet from aqueous solution. Int. J. Biol. Macromol. 2018, 119, 255-269. [CrossRef]

30. Rahmani, Z.; Sahraei, R.; Ghaemy, M. Preparation of spherical porous hydrogel beads based on ion-crosslinked gum tragacanth and graphene oxide: Study of drug delivery behavior. Carbohydr. Polym. 2018, 194, $34-42$. [CrossRef]

31. Martín-Alfonso, J.E.; Číková, E.; Omastová, M. Development and characterization of composite fibers based on tragacanth gum and polyvinylpyrrolidone. Compos. B Eng. 2019, 169, 79-87. [CrossRef]

32. Pandey, V.S.; Verma, S.K.; Yadav, M.; Behari, K. Guar gum-g $N, N^{\prime}$-dimethylacrylamide: Synthesis, characterization and applications. Carbohydr. Polym. 2014, 99, 284-290. [CrossRef] [PubMed]

33. Zhao, M.; Tesfay Reda, A.; Zhang, D. Reduced Graphene Oxide/ZIF-67 Aerogel Composite Material for Uranium Adsorption in Aqueous Solutions. ACS Omega 2020, 5, 8012-8022. [CrossRef] [PubMed]

34. Wu, J.; Wei, Y.; Ding, H.; Wu, Z.; Yang, X.; Li, Z.; Huang, W.; Xie, X.; Tao, K.; Wang, X. Green Synthesis of 3D Chemically Functionalized Graphene Hydrogel for High-Performance $\mathrm{NH}_{3}$ and $\mathrm{NO}_{2}$ Detection at Room Temperature. ACS Appl. Mater. Inter. 2020, 12, 20623-20632. [CrossRef]

35. Mallakpour, S.; Tabesh, F. Tragacanth gum based hydrogel nanocomposites for the adsorption of methylene blue: Comparison of linear and non-linear forms of different adsorption isotherm and kinetics models. Int. J. Biol. Macromol. 2019, 133, 754-766. [CrossRef]

36. Khraisheh, M.A.M.; Al-Ghouti, M.A.; Allen, S.J.; Ahmad, M.N.M. The effect of pH, temperature, and molecular size on the removal of dyes from textile effluent using manganese oxides-modified diatomite. Water Environ. Res. 2004, 76, 2655-2663. [CrossRef]

37. Al-Ghouti, M.A.; Da'ana, D.; Abu-Dieyeh, M.; Khraisheh, M. Adsorptive removal of mercury from water by adsorbents derived from date pits. Sci. Rep. 2019, 9, 1-15. [CrossRef]

38. Mei, J.; Zhang, H.; Li, Z.; Ou, H. A novel tetraethylenepentamine crosslinked chitosan oligosaccharide hydrogel for total adsorption of Cr (VI). Carbohydr. Polym. 2019, 224, 115154. [CrossRef] 
39. Li, Y.-S.; Li, T.-T.; Song, X.-F.; Yang, J.-Y.; Liu, G.; Qin, J.-T.; Dong, Z.-B.; Chen, H.-G.; Liu, Y. Enhanced adsorption-photocatalytic reduction removal for $\mathrm{Cr}(\mathrm{VI})$ based on functionalized $\mathrm{TiO}_{2}$ with hydrophilic monomers by pre-radiation induced grafting-ring opening method. Appl. Surf. Sci. 2020, 514, 145789. [CrossRef]

40. Vilela, P.B.; Dalalibera, A.; Duminelli, E.C.; Becegato, V.A.; Paulino, A.T. Adsorption and removal of chromium (VI) contained in aqueous solutions using a chitosan-based hydrogel. Environ. Sci. Pollut. Res. 2019, 26, 28481-28489. [CrossRef]

(C) 2020 by the authors. Licensee MDPI, Basel, Switzerland. This article is an open access article distributed under the terms and conditions of the Creative Commons Attribution (CC BY) license (http://creativecommons.org/licenses/by/4.0/). 